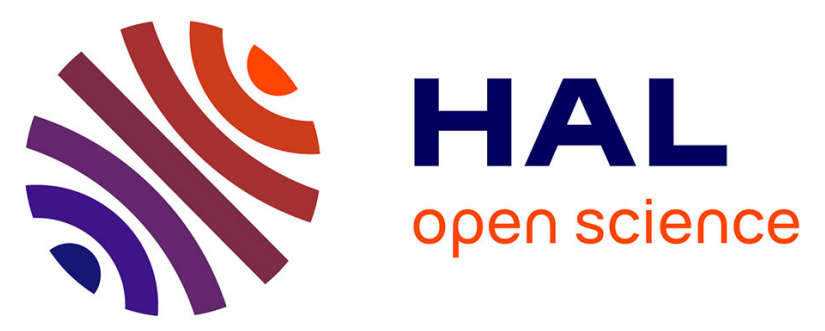

\title{
Insights into hydrological regime of Lake Vostok from differential behavior of deuterium and oxygen-18 in accreted ice
}

\author{
A. A. Ekaykin, V. Y. Lipenkov, J.R. Petit, S. Johnsen, Jean Jouzel, Valérie \\ Masson-Delmotte
}

\section{To cite this version:}

A. A. Ekaykin, V. Y. Lipenkov, J.R. Petit, S. Johnsen, Jean Jouzel, et al.. Insights into hydrological regime of Lake Vostok from differential behavior of deuterium and oxygen-18 in accreted ice. Journal of Geophysical Research. Oceans, 2010, 115, pp.C05003. 10.1029/2009JC005329 . insu-00653223

\section{HAL Id: insu-00653223 \\ https://hal-insu.archives-ouvertes.fr/insu-00653223}

Submitted on 6 Jan 2022

HAL is a multi-disciplinary open access archive for the deposit and dissemination of scientific research documents, whether they are published or not. The documents may come from teaching and research institutions in France or abroad, or from public or private research centers.
L'archive ouverte pluridisciplinaire HAL, est destinée au dépôt et à la diffusion de documents scientifiques de niveau recherche, publiés ou non, émanant des établissements d'enseignement et de recherche français ou étrangers, des laboratoires publics ou privés.

$$
\text { Copyright }
$$




\title{
Insights into hydrological regime of Lake Vostok from differential behavior of deuterium and oxygen-18 in accreted ice
}

\author{
A. A. Ekaykin, ${ }^{1}$ V. Y. Lipenkov, ${ }^{1}$ J. R. Petit, ${ }^{2}$ S. Johnsen, ${ }^{3}$ J. Jouzel, ${ }^{4}$ \\ and V. Masson-Delmotte ${ }^{4}$ \\ Received 13 February 2009; revised 27 October 2009; accepted 5 November 2009; published 4 May 2010.
}

[1] We use isotopic data (deuterium and oxygen-18) of the recently recovered deepest Vostok ice core section (down to $3650 \mathrm{~m}$ depth) to study processes leading to the formation of lake ice and the hydrological regime of subglacial Lake Vostok. The significant variability of the lake ice isotopic content implies fluctuations in physical conditions of ice formation (mainly, volume and/or growth rate of frazil ice crystals) as well as variations of the isotope composition of the freezing water. The latter implies a poor mixing of the source waters (glacier melt and hydrothermal water) with the water of the main lake body. Poor mixing within the lake may have important consequences for the lake's chemical and gas balance and, particularly, for its microbiological content. A poorly mixed lake may provide ecological niches where microbial life can hide from high oxygen concentrations likely typical for the lake. We also show that the isotopic content of the main lake's input (meltwater) significantly differs from that of the output (lake ice), which can be explained by the contribution of an additional (hydrothermal) source. This latter conclusion is supported by the observed noncovariant behavior of deuterium and oxygen-18 isotopes in the lake ice.

Citation: Ekaykin, A. A., V. Y. Lipenkov, J. R. Petit, S. Johnsen, J. Jouzel, and V. Masson-Delmotte (2010), Insights into hydrological regime of Lake Vostok from differential behavior of deuterium and oxygen-18 in accreted ice, J. Geophys. Res., 115, C05003, doi:10.1029/2009JC005329.

\section{Introduction}

[2] The direct study of the Earth's largest subglacial Lake Vostok (LV) began in 1998 when deep borehole 5G-1 at Russian Vostok station entered into the lake ice at the depth of $3539 \mathrm{~m}$ [Jouzel et al., 1999]. In February 1998, the drilling was stopped at the depth of $3623 \mathrm{~m}$. Since then a number of studies have been devoted to the microbiological [Bulat et al., 2004; Christner et al., 2006], gas [JeanBaptiste et al., 2001, 2003; Lipenkov and Istomin, 2001; McKay et al., 2003], chemical [de Angelis et al., 2005; Mayer et al., 2003; Siegert et al., 2003] and mineral [Delmonte et al., 2004; Leitchenkov et al., 2005, 2007; Royston-Bishop et al., 2005] content of the lake ice, and to its physical properties [Hori et al., 2004; Montagnat et al., $2001]$. Isotopic composition in deuterium $(\delta \mathrm{D})$ and oxygen-18 $\left(\delta^{18} \mathrm{O}\right)$ was first considered by Jouzel et al. [1999] and interpreted as a clear fingerprint of the isotopic modifications resulting from a freezing process in accordance with fractionation effects occurring during this phase

\footnotetext{
${ }^{1}$ Arctic and Antarctic Research Institute, St. Petersburg, Russia.

${ }^{2}$ Laboratoire de Glaciologie et Geophisique de l'Environnement, St. Martin d'Hères, France.

${ }^{3}$ Niels Bohr Institute, Copenhagen, Denmark.

${ }^{4}$ Laboratoire des Sciences du Climat et de l'Environnement, CEA, Gif-sur-Yvette, France.

Copyright 2010 by the American Geophysical Union. 0148-0227/10/2009JC005329
}

change. This approach was further developed by Souchez et al. [2000], who suggested a mechanism of lake ice formation assuming accretion of frazil ice crystals at the bottom of the ice cover followed by slow freezing of the host water, and by Souchez et al. [2004], where a simple LV isotopic model was presented. Souchez et al. [2004] found that the lake's relatively short renewal time (compared with its age) requires that the isotopic composition of the meltwater, which feeds LV and the accreted ice should be similar. These authors suggested that the observed shift in the accreted ice deuterium excess $\left(d x s=\delta \mathrm{D}-8^{*} \delta^{18} \mathrm{O}\right.$, where 8 is a typical slope between $\delta \mathrm{D}$ and $\delta^{18} \mathrm{O}$ in meteoric water and ice [Craig, 1961]) with respect to the value expected for meltwater resulted from the influence of hydrothermal waters, an assumption further examined by Petit et al. [2005]. This assumption, first discussed by Jean-Baptiste et al. [2001] was confirmed by the discovery of thermophile bacteria in the lake ice [Bulat et al., 2004]. It has now been supported by other evidence, such as microseismic activity in LV area [Studinger et al., 2003], mineral [Leitchenkov et al., 2005] and chemical [de Angelis et al., 2004] content of inclusions in the lake ice.

[3] Figure 1 is a geographic layout of the southern part of LV where the studied lake ice has been formed. The ice flow line passing through Vostok Station originates at Ridge B (beyond the left limit of Figure 1), about $370 \mathrm{~km}$ to the west from the station. About $60 \mathrm{~km}$ northwest from Vostok, the glacier descends to the LV valley and contacts the lake water. 


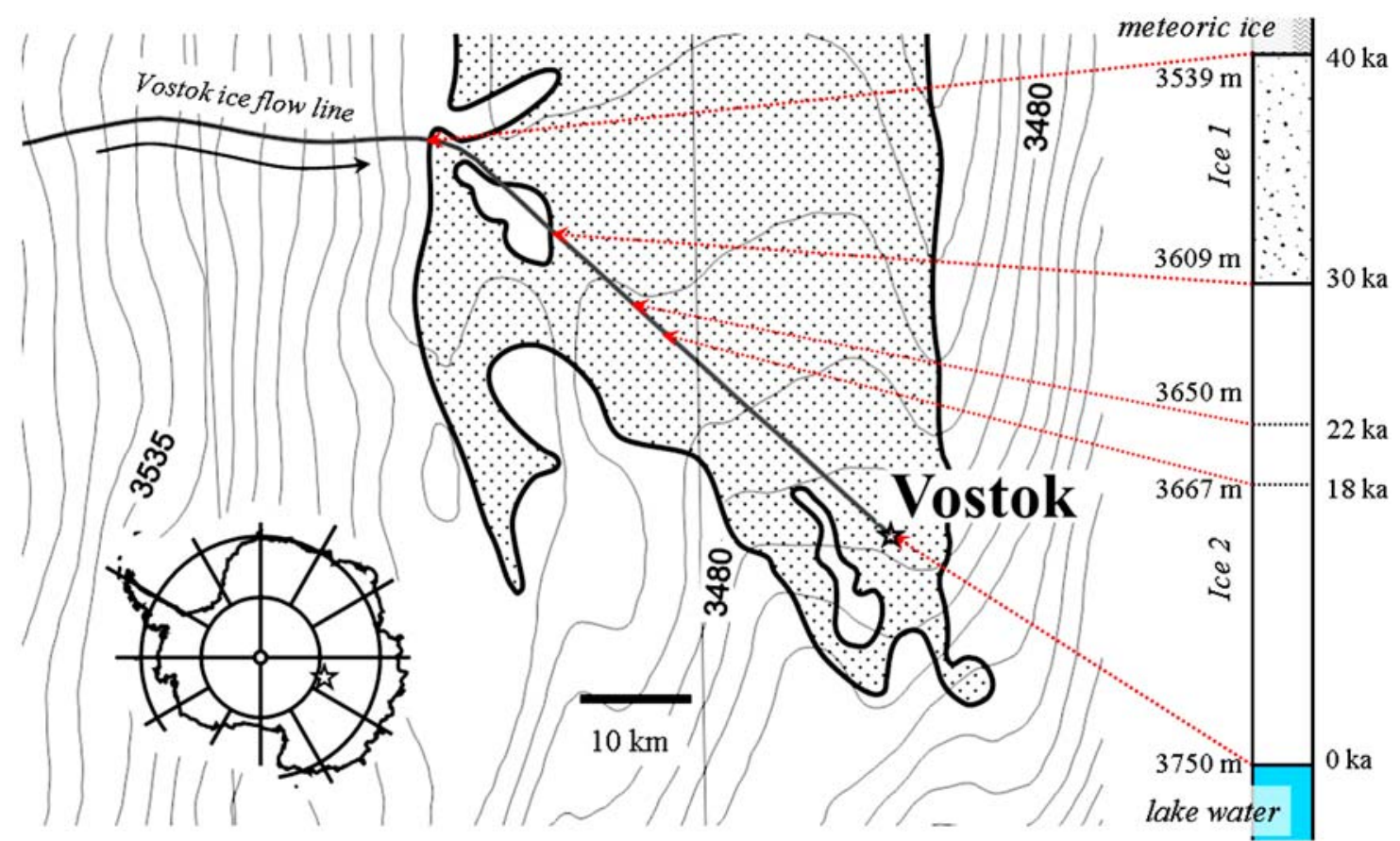

Figure 1. Map of the southern part of Lake Vostok showing location of the Vostok Station and the ice flow line passing through borehole $5 \mathrm{G}-1$. The lake shoreline is plotted using the ground-based radio echo sounding data [Popov and Masolov, 2007]; the position of the flow line is from Tsyganova and Salamatin [2004]. A scheme of the Vostok ice core (on the right) shows the ages and the ice formation sites for a number of reference depth levels in the ice sheet (3539 m is the meteoric to accreted ice transition, $3609 \mathrm{~m}$ is the transition between Lake Ice 1 and Ice $2,3650 \mathrm{~m}$ is the bottom of the ice core studied in this paper, $3667 \mathrm{~m}$ is the current depth of hole $5 \mathrm{G}-1$, and $3750 \mathrm{~m}$ is the approximate depth of the ice-water interface), as inferred from the ice flow modeling [Salamatin et al., 2010].

This is followed by the formation of accreted ice on the lake ceiling. In 5G-1 ice core this transition from glacier (meteoric) to lake (accreted) ice is found at the depth of $3539 \mathrm{~m}$ by a drastic reduction of the isotopic variability, as well as by changes of the $d x s$ parameter (from value of about $14 \%$ typical for glacier ice to about 7\%o) and of the deuteriumoxygen-18 slope (from about 8 to 4 ).

[4] It takes about 40,000 years for the ice to travel from the lake west coast to the Vostok site [Salamatin et al., 2010], and a total thickness of about $210 \mathrm{~m}$ (3539-3750) of the accreted ice is grown on the glacier's bottom during this time period. In the western part of the flow line the ice crosses an island separated from the coast by a strait [Popov and Masolov, 2007]. It is supposed to be here that the $70 \mathrm{~m}$ thickness (3539-3609) of lake ice with visible mineral inclusions (so-called "Lake Ice 1") was formed. About $45 \mathrm{~km}$ from the station the glacier enters an open deep part of the lake where the formation of clean Lake Ice 2 likely took place.

[5] In December 2005, the deep drilling project was resumed by Russian Antarctic Expedition. In January 2009 the 5G-1 borehole was abandoned at the depth of $3667 \mathrm{~m}$ due to a drill accident, and a new borehole (5G-2) was commenced from the depth of $3598 \mathrm{~m}$. Deuterium and oxygen-18 ratios have now been measured in the $5 \mathrm{G}-1$ core interval down to $3650 \mathrm{~m}$ allowing to characterize the isotopic properties of the $41 \mathrm{~m}$ segment of Lake Ice 2 below $3609 \mathrm{~m}$.
[6] Here, we present these new data (3611-3650 m) and, based on an improved lake isotopic model, discuss the isotopic variability in the whole available lake ice core sequence taking into account the quality (signal-to-noise ratio) of the data. It is shown that the isotopic content of the lake ice is subjected to short-term (i.e., much shorter than the lake's renewal time) variability due to a number of factors related to physical conditions at the ice-water interface and to the variability of the lake water isotope composition. Finally, assuming that LV is in steady state, we provide an estimate of all components of its mass balance.

\section{Methods and Results}

[7] Initial measurements of the isotope content in lake ice by Jouzel et al. [1999] showed that its variability is $1-2$ orders of magnitude less than in meteoric snow and ice (Table 1). Typical standard deviation (SD) of individual values in the lake ice isotopic profiles is 0.6 and $0.07 \%$, for $\delta \mathrm{D}$ and $\delta^{18} \mathrm{O}$, which is very close to the reproducibility of routine mass spectrometric measurements. Thus, the accuracy of isotopic measurements is the first issue to be discussed here with the focus on signal-to-noise ratio.

[8] Special attention must be paid to the quality of deuterium measurements. This is because $\delta \mathrm{D}$ in lake ice is related to $\delta^{18} \mathrm{O}$ with the slope of about 4 [Jouzel et al., 1999], while the standard measurement error is roughly 10 times higher for deuterium than for oxygen-18 $(0.5 / 0.05)$. Thus, 
Table 1. Variability of Isotopic Content in Different Vostok Snow and Ice Series ${ }^{\mathrm{a}}$

\begin{tabular}{|c|c|c|c|c|}
\hline \multirow[b]{2}{*}{ Series } & \multirow[b]{2}{*}{ Isotopic Series } & \multicolumn{2}{|c|}{ Maximum Magnitude (\%o) } & \multirow[b]{2}{*}{ Reference } \\
\hline & & $\delta \mathrm{D}$ & $\delta^{18} \mathrm{O}$ & \\
\hline 1 & LV ice, 3539-3650 m interval, resolution $0.5-1 \mathrm{~m}$ & 3.8 & 0.5 & This work \\
\hline 2 & Meteoric ice to lake ice transition, resolution $0.1 \mathrm{~m}$ & 11.5 & 2.1 & [Jouzel et al., 1999] \\
\hline 3 & Last Glacial Maximum to Holocene optimum transition, resolution $1 \mathrm{~m}$ & 59 & 7.6 & [Petit et al., 1999] \\
\hline 4 & Upper $3 \mathrm{~m}$ of snow cover at Vostok, resolution $0.02 \mathrm{~m}$ & 80 & 10.2 & [Ekaykin et al., 2002] \\
\hline 5 & Seasonal changes of isotopic composition of snow precipitation at Vostok, daily resolution & 165 & 23.2 & [Ekaykin et al., 2004] \\
\hline
\end{tabular}

${ }^{\mathrm{a}}$ For all series except 1 signal-to-noise ratio is $\gg 1$; deuterium-oxygen-18 slope is close to 8 in series $3-5$.

with the same relative quality of isotopic measurements the signal-to-noise ratio for $\delta^{18} \mathrm{O}$ is 2.5 times larger than for $\delta \mathrm{D}$.

[9] To increase the reliability of $\delta \mathrm{D}$ data, multiple measurements of each sample are necessary, desirably from different laboratories. Due to the low variability of lake ice isotopic composition, the "memory effect" in mass spectrometric analyses is negligible for these samples, so a random order of sample measurements is used, which allows us to rule out artificial trends.

[10] Isotope analyses of different sections of accretion ice from Lake Vostok have been performed in 1998-2007 in three laboratories: Laboratoire des Sciences du Climat et de l'Environnement (LSCE, Saclay, France), Niels Bohr Institute (NBI, Copenhagen, Denmark), and Russian Geological Institute (VSEGEI, St. Petersburg, Russia). Initial measurements of isotopic $\left(\delta \mathrm{D}\right.$ and $\left.\delta^{18} \mathrm{O}\right)$ content of lake ice were made in 1998 in $1 \mathrm{~m}$ samples from the $3539-3611 \mathrm{~m}$ interval at LSCE [Jouzel et al., 1999], using a routine technique [Stievenard et al., 1994], with reported reproducibility of 0.5 and $0.05 \%$, respectively. These values are shown in Figure 2 as dots. Several measurements (5 for oxygen-18 and 6 for deuterium, as shown by crosses in the Figure 2) demonstrate values that deviate significantly from the mean of the isotopic series, and thus are likely measurement errors. Note that for $\delta^{18} \mathrm{O}$ all the five outbreaks are above the mean level, which is often observed when leakage of air happens during the oxygen mass spectrometric measurements. Thus we decided to eliminate these suspicious values from the final series, as they may lead to false conclusions during further analyses. Indeed, such outbreaks would cause the appearance of artificial cycles after the smoothing of the series and would artificially increase their correlation if occurring both for $\delta \mathrm{D}$ and $\delta^{18} \mathrm{O}$.

[11] In the 3611-3623 $\mathrm{m}$ interval, deuterium was measured in 2005 at VSEGEI and LSCE with reproducibility of $0.45 \%$ in $50 \mathrm{~cm}$ samples. Oxygen-18 from this interval was determined at NBI (2002), LSCE (2002) and VSEGEI (2004). Each sample was thus measured at least three times, which allowed us to achieve very high precision of data in this interval (the standard deviation of the mean value of measurements for a given sample is $0.023 \%$ ). The results are shown in Figure 3 to illustrate the importance of such interlaboratory comparisons. We believe that the short-term variations in most cases correspond to measurement noise. As a result, it is only by averaging data obtained at different laboratories that we have confidence in the observed variations and trends. Note also a systematic offset of about $0.1 \%$ between series measured in different laboratories. Before constructing the stacked records, all the isotopic data $\left(\delta \mathrm{D}\right.$ and $\left.\delta^{18} \mathrm{O}\right)$ from all the intervals were reduced to the level of LSCE measurements for 3539-3611 m interval, so no artificial bias is expected for the series presented in Figure 2.

[12] The ice core section from interval 3623-3650 $\mathrm{m}$ was obtained during the drilling operation carried out in the period 31 December 2005 to 22 January 2006 by specialists

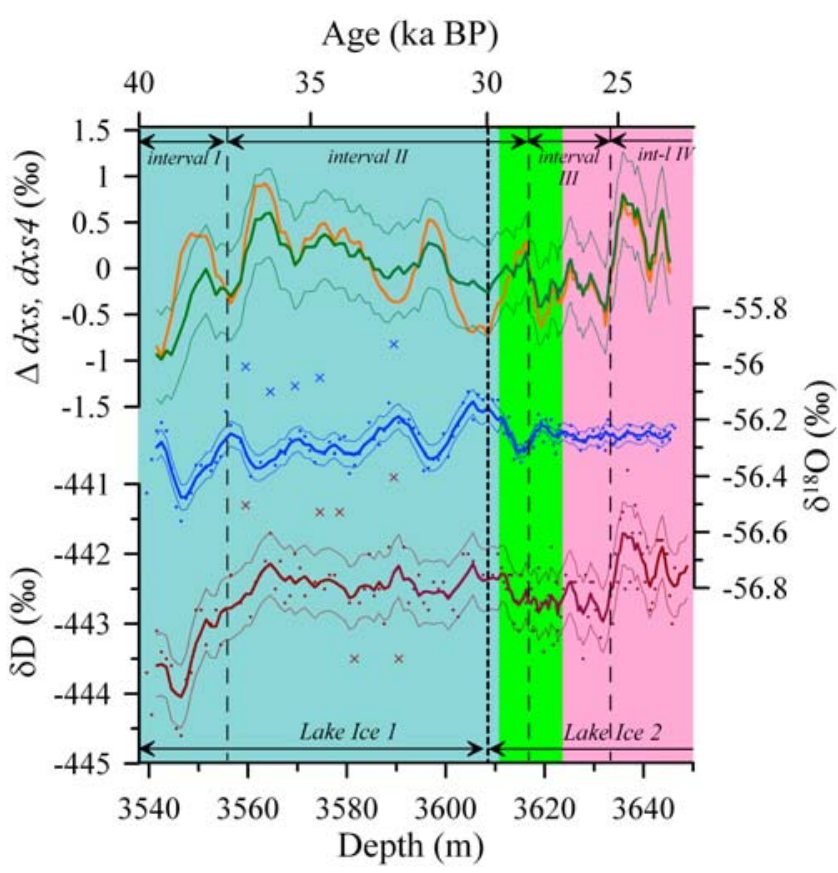

Figure 2. Isotopic composition of ice (deuterium, oxygen$18, d x s$, and $d x s 4$ ) between 3539 and $3650 \mathrm{~m}$ of the Vostok core. Dots represent individual data points, whereas crosses indicate measurements that were rejected after revisiting the previously published data set for the 3539-3611 m depth interval (see text). Thick curves are five data points running means, thin curves denote error bars. The vertical scale for $\delta^{18} \mathrm{O}$ is $1 / 4$ of that for $\delta \mathrm{D}$ to facilitate visual comparison between the two isotopes. The $d x s$ and $d x s 4$ are shown at the top as deviations from their mean values by orange and green curves, respectively. Intervals I-IV are sections of the ice core with different behavior of the isotopic content of ice (see Table 2 and text for explanations). The transition between Lake Ice 1 and 2 is shown by the thick dashed line. Ice core sections measured in different laboratories and/ or at different times are distinguished by different colors. The age scale on the top horizontal axis is calculated according to Salamatin et al. [2010]. Note a nonlinear function between depth and age due to the fact that the accretion rate and the ice flow velocity has changed in the past. 


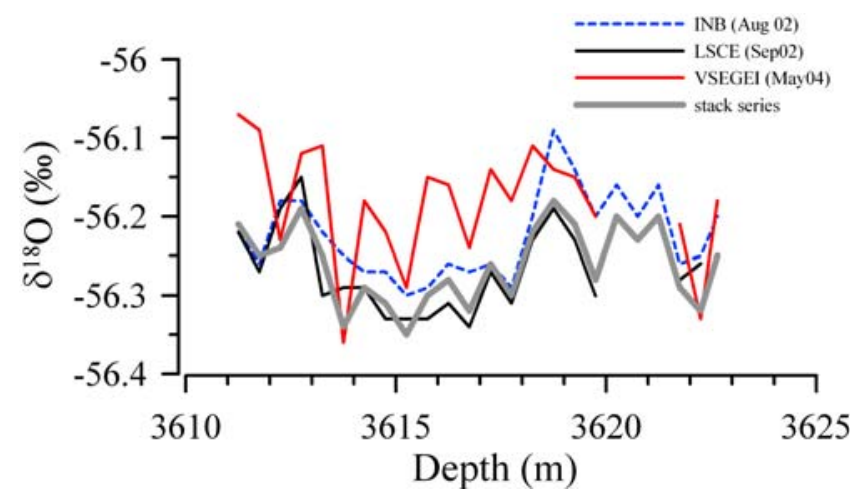

Figure 3. Results of isotopic measurements between 3611 and $3623 \mathrm{~m}$ of the Vostok 5G-1 ice core performed at three different laboratories. The thick gray line represents the stack series reduced to the LSCE data level. Note a tiny $(0.15 \%)$ absolute magnitude of oxygen- 18 variations in this depth interval.

of St. Petersburg Mining Institute using an electromechanical drill [Kudryashov et al., 2000]. The drilling was performed in the routine regime, which allowed obtaining a high-quality ice core, with a very low likelihood of sample contamination. The isotopic samples were taken continuously by cutting a thin slice from the cleaned side surface of the core along its main axis. Ice samples were then melted in sealed plastic bags, poured into waterproof plastic bottles ( 2 aliquots per sample) and sent frozen to the aforementioned laboratories for analysis. Samples were kept under negative temperature until measurement. Generally, all the operations of sample preparation, transportation, storage, and measurement were carried out in the same way as the whole upper Vostok ice core, using the techniques developed during the long-lasting French-Russian cooperation in the frame of the "Vostok" project. Interval 3623-3646.5 m was measured at LSCE in 2007 for both $\delta \mathrm{D}$ and $\delta^{18} \mathrm{O}$ with reproducibility of 0.5 and $0.035 \%$, correspondingly, in $50 \mathrm{~cm}$ samples. Interval $3646.5-3650 \mathrm{~m}$ was measured for $\delta \mathrm{D}$ only at VSEGEI with reproducibility not worse than $0.5 \%$. In Figure 2 we presented the final isotopic series from the interval $3539-3650 \mathrm{~m}$ of the Vostok $5 \mathrm{G}-1$ ice core. In order to reduce the measurement noise, we calculated fiveelement running means.

[13] The isotopic series may be visually divided into several intervals according to their variability. The characteristics of each interval, summarized in Table 2, are discussed in detail in section 4.1, while here we examine the ratio between the accuracy of the isotopic data and the observed variability. The thin lines in Figure 2 show the error bars, $\pm 2 e_{a v}$, where $e_{a v}=\frac{e}{\sqrt{5}}, e$ corresponding to the measurement errors as reported above for each series. One can see that for $\delta^{18} \mathrm{O}$ the measurement accuracy is sufficient for the purposes of our study (see Table 2), while in intervals III and IV $(3617-3650 \mathrm{~m})$ the apparently low signal-to-noise ratio is due to low natural variability, rather than to measurement noise. For $\delta \mathrm{D}$, the isotopic signal/noise ratio seems to be high enough only for intervals I and IV where the variability is the highest. Thus we conclude that interpretation of the deuterium series from the core section between 3557 and $3633 \mathrm{~m}$ must be made cautiously. However, if we consider the whole intervals of Lake Ice 1 and 2, the signal-to-noise ratio appears to be sufficiently high for our study. Note also that the boundaries between intervals I-IV do not correspond to the boundaries between series measured at different laboratories and/or in different time, which confirms that no artificial heterogeneity has been introduced.

[14] Another aspect of isotopic data reliability is related to the fact that short-term isotopic variations tend to be weakened or erased due to diffusion of water molecules in ice [Johnsen et al., 2000]. The rate of smoothing is mainly dependent on ice temperature and age. It can be significant (though difficult to calculate) for the lake ice, as its temperature $\left(-5.5^{\circ} \mathrm{C}\right.$ at the depth of $\left.3620 \mathrm{~m}\right)$ is very close to the pressure melting point $\left(-3.5^{\circ} \mathrm{C}\right.$ at the ice-water interface), and the presence of liquid water may considerably speedup molecular diffusion [Rempel and Wettlaufer, 2003].

[15] We use the detailed $(10 \mathrm{~cm})$ isotopic profile in the glacier-lake ice transition zone in order to determine an effective "diffusion length" $\left(L_{e f}\right)$, a parameter describing the diffusive smoothing rate [Johnsen et al., 2000]. We assume that the initial boundary was a step-like one, and that the presently observed wide transition zone $(40 \mathrm{~cm}$ in length, 3538.4-3538.8 m [Jouzel et al., 1999]) results from molecular diffusion only (Figure 4). The calculated best fit $L_{e f}$ has a plausible value of $7.6 \mathrm{~cm}$ which corresponds to an ice age of $43 \mathrm{ka}$ at the depth $3539 \mathrm{~m}$, very close to the age estimate obtained by a 2D Vostok ice flow line modeling [Salamatin et al., 2010]. Assuming both estimations are correct, then the observed smoothing can be solely explained by diffusion in ice grains, with negligible diffusion in the intercrystalline channels, likely due to huge size and perfect crystalline structure of these grains [Montagnat et al., 2001].

[16] The transition between two types of ice shown in Figure 4 has the same width $(40 \mathrm{~cm})$ for $\delta \mathrm{D}$ and $\delta^{18} \mathrm{O}$. This

Table 2. Statistical Characteristics of the Vostok Lake Ice Isotopic Variability ${ }^{\mathrm{a}}$

\begin{tabular}{|c|c|c|c|c|c|c|}
\hline Statistical Characteristics & Interval I & Interval II & Interval III & Interval IV & Ice 1 & Ice 2 \\
\hline Depth (m) & 3539-3557 & $3557-3617.5$ & $3617.5-3633.0$ & $3633.0-3650$ & 3539-3609 & $3609-3650$ \\
\hline Mean value of $\delta \mathrm{D} / \delta^{18} \mathrm{O}^{\mathrm{b}}(\%)$ & $-443.4 /-56.36$ & $-442.4 /-56.27$ & $-442.7 /-56.25$ & $-442.1 /-56.25$ & $-442.7 /-56.30$ & $-442.4 /-56.25$ \\
\hline $\mathrm{SD}$ of $\delta \mathrm{D} / \delta^{18} \mathrm{O}^{\mathrm{b}}(\%)$ & $0.6 / 0.11$ & $0.3 / 0.07$ & $0.4 / 0.04$ & $0.53 / 0.02$ & $0.6 / 0.09$ & $0.5 / 0.04$ \\
\hline Measurement error (\%) & $0.5 / 0.05$ & $0.49 / 0.04$ & $0.48 / 0.03$ & $0.45 / 0.035$ & $0.5 / 0.05$ & $0.48 / 0.032$ \\
\hline Signal/noise ratio of $\delta \mathrm{D} / \delta^{18} \mathrm{O}^{\mathrm{c}}$ & $3 / 9$ & $\ll 1 / 8$ & $\ll 1 / 0.2$ & $0.7 / \ll 1$ & $3.6 / 9$ & $0.9 / 1$ \\
\hline$\delta \mathrm{D}-\delta^{18} \mathrm{O}$ correlation & $0.65 \pm 0.2$ & $0.4 \pm 0.1$ & $0.2 \pm 0.2$ & $-0.2 \pm 0.2$ & $0.6 \pm 0.1$ & $0.16 \pm 0.12$ \\
\hline$\delta \mathrm{D}-\delta^{18} \mathrm{O}$ slope & $4.0 \pm 1.3$ & $0.9 \pm 0.3$ & $1.3 \pm 1.6$ & $-7 \pm 7$ & $4.0 \pm 0.6$ & $2 \pm 1.6$ \\
\hline Trend of $\delta \mathrm{D} / \delta^{18} \mathrm{O}(\% / \mathrm{m})$ & $\mathbf{0 . 0 8} / 0.004$ & $-0.002 / \mathbf{0 . 0 0 1 6}$ & $-0.008 /-\mathbf{0 . 0 0 2}$ & $-0.01 /-0.0003$ & $0.016 / 0.003$ & $\mathbf{0 . 0 1 7} /-0.0002$ \\
\hline
\end{tabular}

${ }^{a}$ Statistically significant correlations, slopes, and trends are in bold.

${ }^{\mathrm{b}}$ These characteristics were calculated on unsmoothed data, while in the other cases smoothed series were used.

"Signal" is defined as the total dispersion (squared SD) of series minus the square of the measurement error, the latter representing "noise." 


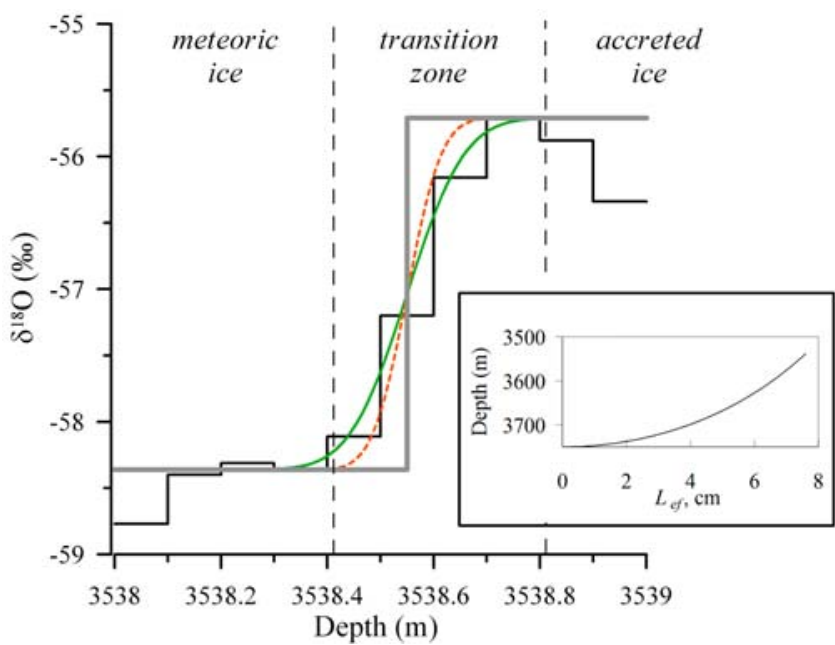

Figure 4. Isotopic composition of the Vostok ice core in the transition zone from glacier to lake ice. The thin black line shows measured $\delta^{18} \mathrm{O}$ profile, whereas the thick gray one denotes the assumed initial step-like transition between the two types of ice. The thin curves correspond to simulated $\delta^{18} \mathrm{O}$ profiles after diffusive smoothing for the two extreme estimates of the lake ice age at this depth for $20 \mathrm{ka}$ (orange) and $50 \mathrm{ka}$ (green), assuming no significant contribution from the water molecule diffusion in the intercrystalline channels (see text). The corresponding effective "diffusion lengths" $L_{e f}$ are 5.1 and $8.5 \mathrm{~cm}$ (the best fit value equals $7.6 \mathrm{~cm}$ ). The inset shows the $L_{e f}$ distribution within the lake ice assuming $L_{e f}=7.6 \mathrm{~cm}$ at $3539 \mathrm{~m}$ and $L_{e f}=0 \mathrm{~cm}$ at the ice-water interface (about $3750 \mathrm{~m}$ ).

means that the available data resolution is not sufficient to observe any difference in molecular diffusion of deuterium and oxygen-18 [Johnsen et al., 2000]. Thus, the same $L_{\text {ef }}$ values may be applied for both isotopes for the rough estimates of the diffusive smoothing. Very high resolution measurements would be necessary to identify the anticipated difference in molecular diffusion rate for deuterium and oxygen-18.

[17] The diffusion length gradually decreases with depth, as the lake ice age decreases, reaching the zero value at the ice-water interface (Figure 4, inset). Over the ice core interval presented here, the calculated $L_{e f}$ varies between 7.6 and $5.5 \mathrm{~cm}$. This implies that diffusive smoothing has erased the isotopic signal on the scale of $10-15 \mathrm{~cm}$, but has not affected the $0.5-1 \mathrm{~m}$ isotopic series studied in this paper.

[18] In summary, the observed variability in the lake ice isotopic profiles (Figure 2) contains valuable information on the isotopic processes in lake water and water/ice interface, the data accuracy is also sufficient to study these processes. The only exception is $\delta \mathrm{D}$ for the interval $3557-3633 \mathrm{~m}$ (Interval I).

\section{LV Isotopic Model}

\subsection{Description of the Model}

[19] In order to interpret the lake ice isotopic data, we have adopted a LV isotopic model presented by Ekaykin et al. [2005]. The model takes into account a LV circulation scheme described by Mayer et al. [2003], Siegert et al. [2001], Souchez et al. [2004], Thoma et al. [2007], Walsh [2002], Wells and Wettlaufer [2008], and Wuest and Carmack [2000]. Fresh meltwater ascends along the tilted glacier base from the northern half of the lake to its southern half, partly mixing with deeper (resident) lake water (Figure 5). In the southern part of the lake, where the glacier is thinner, the water enters the freezing zone. Due to the horizontal temperature gradient along the lake's ceiling, frazil crystals form in supercooled conditions and accrete on the glacier's bottom [Souchez et al., 2000]. An additional (hydrothermal) water source is believed to contribute to the lake's isotopic balance [Bulat et al., 2004; Petit et al., 2005]. The model thus takes into account the possibility of noncomplete mixing of glacier meltwater with the resident lake water, the contribution of two water sources, as well as nonstationary scenarios of the LV system.

[20] The water mass $\left(M_{l}\right)$ and isotope $\left(R_{l}\right)$ balance of the lake are expressed by the following equations:

$$
\frac{d M_{l}}{d t}=M_{m e l t}(1-q)
$$

and

$\frac{d\left(M_{l} R_{l}\right)}{d t}=M_{\text {melt }}\left(R_{\text {melt }}-q \alpha\left[R_{\text {melt }}(1-\sigma)+R_{l} \sigma\right]+q_{H T}\left[R_{H T}-R_{l}\right]\right)$.

[21] Here $q$ is the mass ratio of the accretion ice outcome and of the meltwater income $\left(M_{m e l t}\right)$, and $q_{H T}$ is the ratio of the mass income from hydrothermal waters to $M_{\text {melt }}$. We assume the hydrothermal circulation is fed by the lake water, thus does not influencing the mass balance of the lake. $R$ is the isotopic content of melt, resident and hydrothermal waters (corresponding subscripts melt, $l$ and $H T$ ), while $\alpha$ is an effective fractionation coefficient at the water-ice interface assuming that the lake ice is formed by three processes: frazil ice accretion, slow freezing of host water in equilibrium with ice, and freezing of water pocket [Petit et al., 2005; Souchez et al., 2000]. The coefficient $\alpha$ may theoretically change between 1 (for ice only formed by fastly growing frazil crystals under strong supercooling conditions or frozen water pockets) and $1.0208 / 1.003\left(\delta \mathrm{D} / \delta^{18} \mathrm{O}\right)$ for ice formed in equilibrium with water. The coefficient $\sigma$ is the mixing ratio of meltwater and resident lake water; it ranges from 0 to 1 , i.e., from no mixing to complete mixing.

[22] The values of the mixing ratio and of the effective fractionation coefficient determine the relationship between $R_{i c e}$ (isotopic content of accreted ice), $R_{\text {melt }}$ and $R_{l}$

$$
R_{\text {ice }}=\alpha\left(R_{\text {melt }}(1-\sigma)+R_{l} \sigma\right) .
$$

In the case of steady state regime isotopic balance of the lake can be expressed as

$$
R_{\text {ice }}=R_{\text {melt }}+q_{H T}\left(R_{H T}-R_{l}\right) .
$$

This is valid only in the case of hydrothermal circulation fed by lake water, as assumed in our model. Otherwise, if the hydrothermal input represents an independent source 


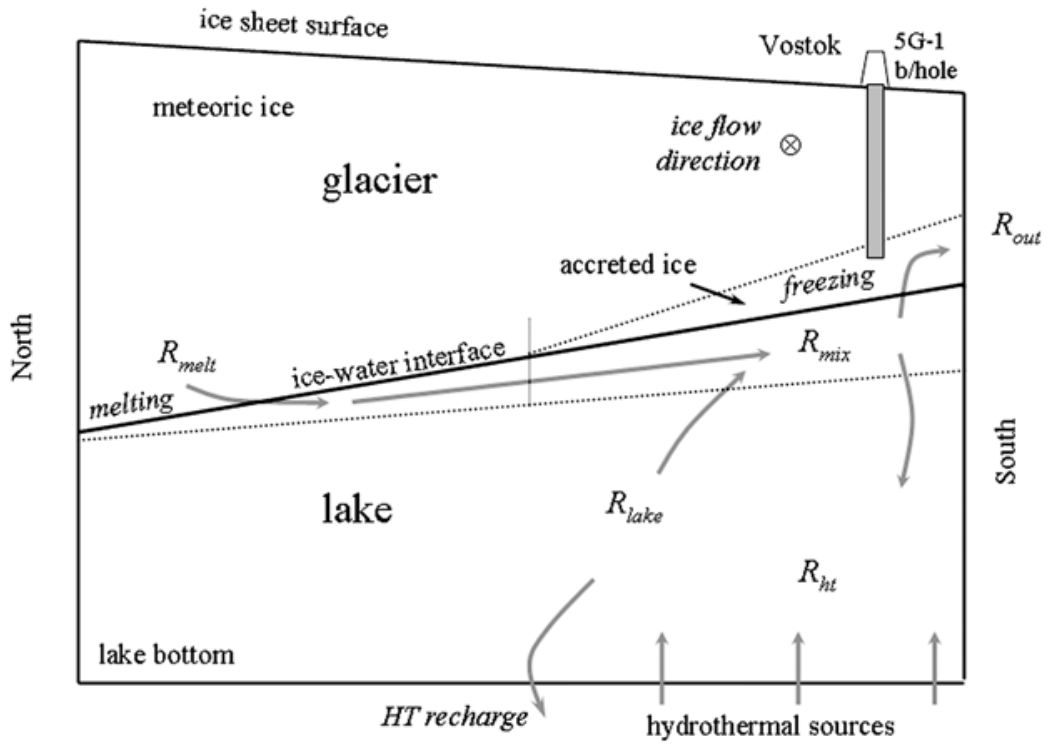

Figure 5. A “1.5 layer" scheme of isotope balance in Lake Vostok (see text for explanations).

(as was suggested in the first version of the model [Ekaykin et al., 2005]), equation (4) becomes

$$
R_{\text {ice }}=(1 / q) R_{\text {melt }}+\left(q_{H T} / q\right) R_{H T}
$$

where $(1 / q)+\left(q_{H T} / q\right)=1$, i.e., the isotopic content of ice is a weighted mean of those of the two water sources. If LV is in zero mass balance, meltwater is completely mixed with resident lake water, and there is no additional water source (i.e., $q=1, \sigma=1, q_{H T}=0$ ) then this model is equivalent to the simplest one described by Souchez et al. [2004].

\subsection{Factors Controlling the Isotopic Variability of Lake Ice}

[23] Factors possibly controlling the isotopic composition of lake ice may be divided into two groups depending on whether they influence the effective fractionation coefficient during ice formation or the isotopic composition of the lake water from which the ice forms. The first group is related to the physical conditions prevailing at the ice-water interface: water supercooling and corresponding crystal growth rate, ice formation mechanisms (proportion of frazil ice crystals and water pockets volume). All these processes result in changes of $\alpha$ and cause parallel changes of deuterium and oxygen-18 with a slope close to 4 (see equation (6)).

[24] The second group is related to the changes of mass discharge and/or of the isotopic content of both water sources of LV (ice melt and hydrothermal water). The resulting variations of the lake ice isotopic content depend on the following parameters: the time scale, the relative contribution of the melt and hydrothermal water sources, and the mixing ratio of source and resident lake water. Let us consider several typical situations, all of which assume steady state in terms of mass balance.

[25] In the case of variations similar to, or longer than, the lake renewal time $\left(\sim 10^{4}\right.$ years $)$, the lake will maintain a zero isotopic balance. So, changes of meltwater isotopic content, according to equation (4), will be directly transferred into changes of accreted ice, $d R_{\text {ice }}=d R_{\text {melt }}$. The corresponding $\mathrm{d} \delta \mathrm{D} / \mathrm{d} \delta^{18} \mathrm{O}$ slope in ice (hereafter $S_{\text {ice }}$ ) will be close to 8 , i.e., to the value typical for glacier ice. Changes of $M_{\text {melt }}$ would be equilibrated by a corresponding change in accreted mass outcome without any modification of $R_{\text {ice }}$.

[26] The isotopic changes of the hydrothermal source will be transferred into the lake ice with a scaling factor $q_{H T}$ : $d R_{\text {ice }}=q_{H T} d R_{H T}$. $S_{\text {ice }}$ will be equal to the corresponding slope in the hydrothermal water $\left(S_{H T}\right)$, though the value of the latter is uncertain, as discussed below. If the hydrothermal input varies, the corresponding changes in lake ice will be equal to $d R_{\text {ice }}=\left(R_{H T}-R_{l}\right) d q_{H T}$, without modification of the lake ice volume.

[27] If the mixing ratio $(\sigma)$ of melt and lake water fluctuates, no changes will occur in the lake ice isotopic content since $\sigma$ does not participate in equation (4). This is explained by the fact that changes of the isotopic content of the mixed water due to variable proportion of meltwater will be compensated by modified value of $R_{l}$, as follows from equation (3). Note that $\sigma$ is inversely proportional to the effective renewal time of the lake (i.e., the renewal time of the resident water). In the extreme case of $\sigma=0, R_{\text {ice }}$ will be solely determined by the meltwater (equation (3)), and deeper lake becomes isolated from the influence of the glacier.

[28] The short-term (shorter than the lake's renewal time) pulsations of the sources will only be reflected in the accreted ice in the case of noncomplete mixing of the source and the lake water, otherwise they will be smoothed out. So, in the case of meltwater we can say that $d R_{\text {ice }}=\alpha(1-\sigma)$ $d R_{\text {melt }}$, which means that more mixing decreases the influence of this factor. The slope $S_{\text {ice }}$ will be equal to $S_{\text {melt }}\left(\alpha_{\mathrm{D}} / \alpha_{18}\right)$, i.e., in the 8 to 8.15 range.

[29] If $\sigma$ fluctuates, the corresponding changes in accreted ice will be equal to $d R_{\text {ice }}=\alpha\left(R_{l}-R_{\text {melt }}\right) d \sigma$, and $S_{\text {ice }}=$ $\frac{\alpha_{D}}{\alpha_{18}} \frac{\left(R_{1}-R_{\text {melt }}\right)_{D}}{\left(R_{1}-R_{\text {met }}\right)_{18}}$. As shown below in section 4.3 .1 (see also Figure 7b), the value of $S_{\text {ice }}$ in this case is between 4 and 8 . Note that fluctuations of the lake ice isotopic composition 
Table 3. Summary of Factors Influencing the Isotopic Composition of LV Ice

\begin{tabular}{lcc}
\hline \multicolumn{1}{c}{ Factor } & $\begin{array}{c}\delta \mathrm{D}-\delta^{18} \mathrm{O} \\
\text { Correlation }\end{array}$ & $\begin{array}{c}\mathrm{d} \delta \mathrm{D} / \mathrm{d} \delta^{18} \mathrm{O} \\
\text { Slope }\end{array}$ \\
\hline $\begin{array}{l}\text { Physical processes of lake ice } \\
\text { formation }\end{array}$ & Good & $\sim 4$ \\
$\begin{array}{l}\text { Meltwater source } \\
\text { Mixing ratio, } \sigma \text { (for short-term } \\
\text { variations) }\end{array}$ & Good & $\sim 8$ \\
Hydrothermal water source & Good & $4-8$ \\
\hline
\end{tabular}

related to this factor may be spatial rather than temporal, because different sections of lake ice were formed at different intervals of the flow line (Figure 1) with likely different access of meltwater from the northern part of LV (melt zone).

[30] A large uncertainty in the variability of the isotopic content of the LV accretion ice is introduced by the influence of the hydrothermal source since little is known about its characteristics. Typical reported $\delta \mathrm{D}-\delta^{18} \mathrm{O}$ slopes for geothermal waters are somewhere between 0 and 4 [Hoefs, 2004]. But these slopes correspond to the line between hydrothermal and local meteoric waters feeding the hydrothermal circulation $\left(S_{w-H T}\right)$. The $\mathrm{d} \delta \mathrm{D} / \mathrm{d} \delta^{18} \mathrm{O}$ slope in the hydrothermal waters $\left(S_{H T}\right)$ may thus be quite different [Polya et al., 2000; Vidal et al., 1981; Vuataz and Goff, 1986; Xu et al., 2006], depending on various factors, among which the most important are the water and rock geochemistry, the groundwater recharge by meteoric waters, the renewal time of underground water pools, the fractionation during separation of vapor fraction. The isotopic alteration of hydrothermal waters has different mechanisms for $\delta \mathrm{D}$ and $\delta^{18} \mathrm{O}$ because of different fractionation coefficients due to exchange with different minerals, and their different temperature and pressure dependences. This weakens the correlation between $\delta \mathrm{D}$ and $\delta^{18} \mathrm{O}$ in hydrothermal waters, and makes the apparent slope between the both isotopes insignificant. In case of $\mathrm{LV}$, additional uncertainty is related to the unknown degree of mixing between hydrothermal and lake waters on the way to the freezing site (the stronger is mixing, the lower is the hydrothermal-related variability in the ice).

[31] We summarized the influence of the factors discussed above on the lake ice isotopic variability in Table 3. The isotopic composition of the lake ice seems thus to bear all the necessary information about the processes lying behind its variations, as all the factors have a distinct isotopic signature. For example, a poor correlation between the two isotopes may indicate the influence of the hydrothermal source.

[32] We propose to separate the lake ice isotopic variability caused by physical conditions at ice-water interface and water isotopic content changes by introducing a new parameter, $d x s 4=\delta \mathrm{D}-4.06 \delta^{18} \mathrm{O}$ (Figure 2). As pointed out by Jouzel and Souchez [1982] and Souchez and Jouzel [1984], the slope between water and ice freezing from this water, $S_{w-i}$, can be estimated as

$$
S_{w-i}=\frac{\left(1+\delta D_{w} / 1000\right)}{\left(1+\delta^{18} O_{w} / 1000\right)} \frac{\left(\alpha_{D}-1\right)}{\left(\alpha_{18}-1\right)} .
$$

[33] The rightmost term of equation (6) is constant except when $\alpha$ approaches unity. So, $S_{w-i}$ is solely determined by the isotopic composition of the lake water with a limited possible range of 4.025 to 4.096 , and a mean of 4.06 (see section 4.3.1). Thus, the $d x s 4$ value of the lake ice is very close to that of the lake water, and remains constant for any $\alpha$ values, i.e., it is independent of physical conditions prevailing at ice formation (Figure 6). As follows from Figure 6, $d x s 4$ value increases if LV water isotopic content increases along the line with the $\delta \mathrm{D} / \delta^{18} \mathrm{O}$ slope $>4$ (meltwater influence) or decreases along the line with the slope $<4$.

[34] We conclude that the isotopic content of LV ice is a complicated function of several factors, each of them having its own isotopic signature. Thus the analysis of the isotopic variability of the LV ice seems to be a powerful tool to study the physical and hydrological processes taking place inside the lake.

\section{Discussion}

\subsection{Interpretation of the Isotopic Variability in the $\mathrm{LV}$} Ice

[35] In this section we use the expected signatures of different factors, as established in the previous section, in order to interpret the isotopic variability in the lake ice depth interval $3539-3650 \mathrm{~m}$. As previously stated, we divide the lake ice core sequence into 4 intervals of different internal isotopic variability (Figure 2 and Table 2).

\subsubsection{Interval I (3539-3557 $\mathrm{m})$}

[36] Interval I (3539-3557 $\mathrm{m}$ ) is characterized by a rapid increase of isotopic values, especially pronounced (and significant) for $\delta \mathrm{D}$. The overall trend is disturbed by the clear minimum at $3547 \mathrm{~m}$ depth with the lowest isotopic

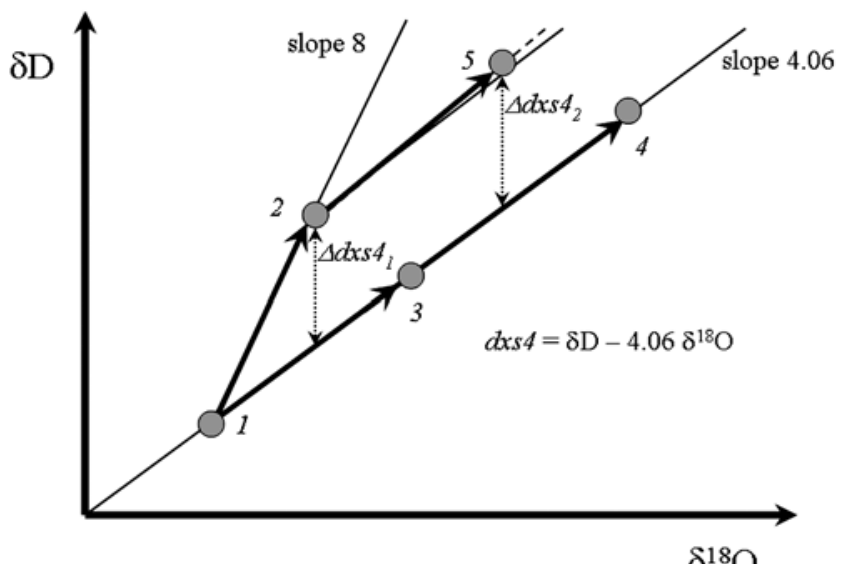

Figure 6. Scheme illustrating the behavior of the $d x_{s} 4$ parameter. The isotopic composition of the lake ice is related to that of the lake water by the line with slope $S_{w-i}=4.06$. The $d x s 4$ parameter calculated as $\delta \mathrm{D}-4.06 * \delta^{18} \mathrm{O}$ is constant along any line with this slope. Thus, the $d x s 4$ value is the same for water (point 1) and for ices formed from this water under different physical conditions (points 3 and 4). If the water isotopic composition changes along a slope different from point 4 (e.g., from points 1 to 2 ), the $d x s 4$ will change by $\Delta d x s 4_{1}$ as illustrated. Ice (point 5 ) formed from water (point 2) has the $d x s 4$ values higher than ice (point 3 ) and ice (point 4), but nearly the same as water (point 2). Note that $d x s 4_{1}<\Delta d x s 4_{2}$ because $S_{w-i}$ slightly depends on the water isotopic composition. 
values for the whole studied lake ice sequence. Deuterium and oxygen-18 in this interval are significantly correlated with a slope $\left(S_{\text {ice }}\right)$ of about 4 . We thus can robustly attribute variations in this interval to the changes of physical conditions during the ice formation (Table 3). Low isotopic values at $3547 \mathrm{~m}$ depth are likely due to fast ice crystal growth in supercooled conditions because of cold glacier contact with comparatively warm lake water [Salamatin et al., 2010]. Maximum $\delta^{18} \mathrm{O}$ shift in this interval (about $0.4 \%$ in the nonsmoothed series) is relatively large and implies a significant change of ice crystal growth rate and/or of the proportion of frazil ice and water pockets. For example, in the case of a $50 \%$ portion of frazil crystals, this $0.4 \%$ increase in $\delta^{18} \mathrm{O}$ in accretion ice means roughly a 2.5 -fold reduction of their growth rate. Alternatively, assuming constant (maximum) frazil growth rate, this $0.4 \%$ increase in $\delta^{18} \mathrm{O}$ suggests a decrease in the contribution of frazil crystal to the forming ice roughly by $1 / 3$.

[37] On this same interval, the $d x s 4$ values (Figure 2) vary by about $1 \%$, which suggests that the isotopic content of water has increased with the slope of $>4$ (Figure 6). Thus, in agreement with the maximum number of mineral inclusions at this depth [Jouzel et al., 1999], the minimum isotopic content at $3547 \mathrm{~m}$ may be related to the reduced access of meltwater to the ice, as it was located close to the grounding line.

[38] A scenario assuming no frazil formation in LV [Salamatin et al., 2010] is hardly able to explain the observed isotopic variability in the lake ice, as it would require a very strong variability of the volume of frozen water pockets (by about $30 \%$ of total ice volume), which is unlikely.

\subsubsection{Interval II (3557-3617.5 m)}

[39] Interval II (3557-3617.5 $\mathrm{m}$ ) is marked by significant quasiperiodic oscillations of $\delta^{18} \mathrm{O}$. This implies noticeable changes of one (or some) of the factors described in section 3.2. We are not able to robustly identify the main involved factor, since deuterium variations are here undistinguishable from the noise (Table 2). Note, however, that the $d x_{s} 4$ parameter varies significantly within this interval, suggesting that the lake ice isotopic variability is explained, at least in part, by the change of the lake water isotopic content.

[40] The boundary between intervals II and III does not correspond to the transition from Lake Ice 1 to Ice 2. From an isotopic point of view this transition is located around the depth of $3617 \mathrm{~m}, 8 \mathrm{~m}$ below the inclusion-based one $(3609 \mathrm{~m})$. This situation mirrors the transition from glacier ice to lake ice, where sharp increase of inclusion number $(3547 \mathrm{~m})$ is $8 \mathrm{~m}$ below the isotopically determined change of ice origin $(3539 \mathrm{~m})$.

\subsubsection{Interval III $(3617.5-3633.0 \mathrm{~m})$}

[41] Interval III $(3617.5-3633.0 \mathrm{~m})$ is characterized by a reduced variability of oxygen-18, accompanied by a $\delta \mathrm{D}$ variability similar to that of interval II. In this respect, this interval may be considered as a transition zone between intervals II and IV. On the other hand, minimum $d x s 4$ values in interval III (compared to intervals II and IV) suggest that this ice was formed under reduced access of meltwater, or increased contribution of hydrothermal waters.

\subsubsection{Interval IV (3633.0-3650 m)}

[42] Interval IV $(3633.0-3650 \mathrm{~m})$ is remarkably different from the overlying ice core sections. The oxygen-18 profile demonstrates the same flat pattern as in interval III (with even lower variability), but the amplitude of the deuterium oscillations increases considerably. Alternatively, the behavior of deuterium in interval IV may be described as a sharp (by about $0.7 \%$ ) shift between 3633 and $3635 \mathrm{~m}$ followed by a "normal" (i.e., similar to previous intervals) variability.

[43] The correlation between the two isotopes is not significant in this interval. Since the deuterium variability considerably exceeds that of oxygen-18 (ratio of standard deviations is about 25), the behavior of $d x s$ and $d x s 4$ parameters is solely determined by (and very similar to) the $\delta \mathrm{D}$ profile. We conclude that the noncovariant behavior of $\delta \mathrm{D}$ and $\delta^{18} \mathrm{O}$ in interval IV indicates the influence of the hydrothermal source (Table 3 ).

\subsubsection{Comparison of Lake Ice 1 and 2}

[44] In Table 2 we summarized the statistical characteristics for the whole available sections of Lake Ice 1 (3539$3609 \mathrm{~m}$, with mineral inclusions) and 2 (3609-3650 m, clean ice). The mean isotopic composition for Ice 1 is slightly lower than for Ice 2, but this is mainly due to low values in the uppermost interval (3539-3557 m). Indeed, without the latter the mean values are very close for the both types of ice. Despite their different short-term variability, these ice sections were thus likely formed in similar conditions. This is easier to explain if we assume that Lake Ice 1 was not formed in a shallow and narrow bay [Bell et al., 2002], but in a relatively deep [see Leitchenkov et al., 2005, Figure 2] strait separated from the main body of the lake by a small island [Popov and Masolov, 2007] (see Figure 1). Since the location of the Vostok ice flow line is not known precisely, and the ice flow may have changed in the past, it is also possible that Ice 1 was not formed over the island, but rather close to its shores. This would better explain the apparent continuity of the ice formation. The mean isotopic content for the whole available lake ice section is -442.6 and $-56.28 \%$ for $\delta \mathrm{D}$ and $\delta^{18} \mathrm{O}$, respectively.

[45] An interesting feature of Ice 1 is the quasiperiodic variability of the isotopic profiles with wavelength of about $20 \mathrm{~m}$; this roughly corresponds to a time period of $3 \mathrm{ka}$ (see the upper horizontal axis in Figure 2). The magnitude of these oscillations (up to about $0.2 \%$ ) implies relatively strong variations of physical conditions of ice formation and/or lake water isotopic content. In future studies we will focus on exploring whether these oscillations are of spatial origin, due to ice traveling through different zones in the lake, or temporal origin, due to changes in the conditions at the site of ice formation.

[46] In general, the isotopic variability in Ice 1 clearly demonstrates the influence of the physical conditions prevailing during ice formation (especially for interval I, 3539$3557 \mathrm{~m}$ ) and very likely of changing isotope content of the freezing water due to varying access of the meltwater. Since the typical time period of isotopic variations discussed here $\left(10^{3}\right.$ years $)$ is considerably shorter than the $\mathrm{LV}$ water renewal time (of the order of $10^{4}$ years), we may assume that mixing of the meltwater with the lake water prior to accretion is poor.

[47] Insufficient mixing of meltwater could explain the suggested undersaturation of the freezing lake water with gases, as evident from the gas content of lake ice [Lipenkov and Istomin, 2001]. Among other consequences, a poor mixing of the lake water implies an increased LV's renewal 
time, which may have important effects on the estimates of its gas and chemical balance. This result may also be potentially important for the evaluation of microbiological content in the lake, since microbial life may find ecological niches to escape from the excessively high oxygen content expected in the main lake body [Lipenkov and Istomin, 2001].

[48] In Ice 2, the very flat profile of oxygen-18 implies stable physical conditions of ice formation and small variations of meltwater influence, while noncovariant behavior of $\delta \mathrm{D}$ and $\delta^{18} \mathrm{O}$ points out to the influence of the hydrothermal sources. However, the very small oxygen-18 variability accompanied by much stronger deuterium oscillations seems to be a very unusual and rare behavior for natural water and needs further evidence, as presented in the next section.

\subsection{Signature of the Variability of Hydrothermal Origin in the $\mathrm{LV}$ Ice}

[49] Following Craig [1963], it has been generally assumed [Petit et al., 2005] that hydrothermal waters are enriched in $\delta^{18} \mathrm{O}$ relative to the lake water, with an unchanged deuterium content. In this case one would rather expect an increased oxygen-18 variability in hydrothermal waters (and thus in the lake ice) compared to the deuterium variability, i.e., a pattern opposite to what is observed in interval IV $(3633-3650 \mathrm{~m})$. However, it is recognized that hydrothermal processes involve also a fractionation of the deuterium [Hoefs, 2004]. As pointed out by Giggenbach [1992, p. 497] "horizontal shifts in ${ }^{18} \mathrm{O}$ at constant $\mathrm{D}$ are the exception rather than the rule for these [geothermal] waters." Deuterium shifts may be caused by the mixing of ground waters with magmatic waters [Giggenbach, 1992], due to mineral water hydrogen isotope fractionation [Criss et al., 1982; Driesner, 1997; Gilg and Sheppard, 1996; Ikingura et al., 1989; Polya et al., 2000; Satake and Matsuo, 1984] or even due to the microbiological activity [Morasch et al., 2001].

[50] Some of the minerals known to exchange with the hydrogen of water (epidote, various micas, chlorite and other clay minerals) have been found in the lake ice mineral inclusions [Leitchenkov et al., 2005, 2007]. Taking into account very high pressures $(>50 \mathrm{MPa})$ occurring in the sublake environment, we note that the deuterium fractionation linked with mineral water interaction may be significantly larger than those predicted by experimental studies [Driesner, 1997]. Another indirect evidence of possible deuterium fractionation in LV hydrological system is the discovery of thermophile bacteria in lake ice that are known to use hydrogen in their nutrition chain [Bulat et al., 2004].

[51] The most distinct feature of the interval IV, practically no oxygen-18 variability accompanied by noticeable deuterium oscillations, is known for the groundwater, too, though relatively rare [Driesner, 1997; Polya et al., 2000 and references herein]. In particular, most (though not all) anomalous (relative to oxygen-18) deuterium variability has been found in crustal, related to ore deposits, fluid inclusions of paleometeoric water and predominantly ascribed to influence of water organic matter (e.g., coals or coaly sediments) interactions [Polya et al., 2000].

[52] This somewhat unexpected $\delta \mathrm{D}$ variability does not imply a stronger hydrothermal fractionation of hydrogen compared to oxygen. Rather, the observed pattern could be explained by a stronger and constant oxygen alteration combined with a weaker but pulsating deuterium fractionation. This pattern would be typical for the case of water in equilibrium with rocks or deposits in terms of oxygen-18, but far from equilibrium relative to deuterium, in such a way that small changes of conditions (temperature, pressure, flow intensity) may be reflected in the resultant $\delta \mathrm{D}$ content of the hydrothermal waters.

[53] The presence of short-term isotopic variations related to the hydrothermal activity implies poor mixing between hydrothermal and lake waters. This may be explained by (1) the formation of rising columnar vortices as suggested by laboratory simulations of LV water circulation [Wells and Wettlaufer, 2008] or (2) by sporadic warm hydrothermal plumes boosted by seismotectonic activity [Studinger et al., 2003], which is in agreement with the chemical composition of the lake ice [de Angelis et al., 2005]. The mentioned vortices would likely develop in the deep open south basin of LV rather than in the shallower and narrower strait. This may explain why the short-term hydrothermal-related variability is found in Ice 2 and not in Ice 1. Enhanced activity of a hydrothermal water source during the formation of accreted ice below $3633 \mathrm{~m}$ is supported by significant increase in the radiogenic crustal helium concentration between 3650 and $3658 \mathrm{M}$ (P. Jean-Baptiste, personal communication, 2009) as compared to previously published helium data extending to $3611 \mathrm{~m}$ depth [Jean-Baptiste et al., 2001].

\subsection{Isotopic Budget of $\mathrm{LV}$}

[54] In this section we estimate the average values of the components of the LV isotopic budget on the time scale of $\sim 20,000$ years covered by the available ice core. To this end, we use both available experimental data and theoretical considerations, assuming that the lake is in steady state.

[55] The only experimentally known component of the LV isotopic balance is the isotopic content of the output (lake ice). As shown below, the isotopic content of the main input source, the glacier meltwater, can be estimated though with some uncertainty. Only very little is known about the possible discharge and the isotopic content of the hydrothermal source, so this term is calculated as the residual of the other terms.

[56] The general assumptions of the LV isotopic balance are as follows: (1) the isotopic composition of the lake ice is related to that of the freezing water by a line with a slope, $S_{w-i}$, of about 4 (equation (6)), and the difference between them is determined by the effective fractionation coefficient (equation (3)); (2) the isotopic composition of the freezing water is the weighted mean of the meltwater and of the resident lake water, (expression in parentheses in equation (3)); (3) the isotopic composition of the lake ice is shifted compared to that of the meltwater due to the influence of hydrothermal source as prescribed by equation (4); and (4) the isotopic composition of the hydrothermal source is determined by that of the resident lake water. Most likely, it is shifted from LV's isotopic composition to the right along the line with a slope $S_{w-H T}$ ranging from 0 to 4 [Hoefs, 2004].

[57] The suggested isotopic balance scheme would not change considerably if LV is a part of one of the active subglacial hydrological systems recently found in Antarctica [Fricker et al., 2007; Wingham et al., 2006]. Indeed, the isotopic composition of subglacial rivers that might flow 
into the LV should be roughly the same as that of the meltwater source considered in this paper. In terms of the isotopic model presented here, the outflow of liquid water from the LV means a lower effective fractionation coefficient between lake water and bulk outcome, and thus can be accounted for. Only in the case if LV behaves like a "captured lake" and experiences periodic "jökulhlaups" [Erlingsson, 2006; Evatt et al., 2006; Pattyn, 2008], may its mass and isotopic balance be significantly disturbed.

\subsubsection{Isotopic Content of Melting Ice and Resident} Water in the Lake

[58] In order to estimate the isotopic content of the meltwater, two more assumptions are needed: (1) The ice that melts in northern half of the LV has its origin in the Dome B area [Petit et al., 2005]. (2) The difference between longterm (of the order of $30 \mathrm{ka}$ ) average values of isotopic composition at Vostok and at Dome B remained constant through time.

[59] The age of the ice melting in the northern part of LV is roughly $700-800 \mathrm{ka}$ [Salamatin et al., 2003], an age much older than reached by the Vostok ice core in its undisturbed part. However, the 3310-3538 m core interval contains ice characterized by a very low isotopic variability with an age likely between 0.4 and $2 \mathrm{Ma}$ [Salamatin et al., 2004]. The mean $\delta \mathrm{D}$ value for this interval is $-457 \%$ with a STD of $8 \%$ for individual values. The Dome B ice core record covers only the last $30 \mathrm{ka}$ with an average $\delta \mathrm{D}$ value of $-439.05 \%$ [Jouzel et al., 1995]. The difference between Dome B and Vostok average deuterium values over the common age interval of these two ice cores $(0-30 \mathrm{ka})$ is about $11.5 \%$. Thus we come to the value of $-445.2 \%$ as an estimation of Dome B ice of 700-800 ka ago representing the meltwater isotopic composition. The same considerations for $\delta^{18} \mathrm{O}$ produce the value of $-57.25 \%$. Figure $7 \mathrm{a}$ illustrates our approach.

[60] Similar calculations based on comparing the Dome B and the EPICA Dome C [Jouzel et al., 2007] isotopic profiles lead to a meltwater isotopic content of $-449 \%$ or $\delta \mathrm{D}$, which is close to the above estimation, and thus confirms our approach. We also used the EDC data to estimate the uncertainty of the meltwater isotopic composition value. As a measure of the uncertainty we took the SD of the 100,000 year mean values of the isotopic record, which equals $2.9 \%$ for $\delta \mathrm{D}$ and $0.36 \%$ for $\delta^{18} \mathrm{O}$. Thus the final values of the $\mathrm{LV}$ meltwater source isotopic content are $-445.2 \pm 2.9 \%$ ( $\delta \mathrm{D})$ and $-57.25 \pm 0.36 \%\left(\delta^{18} \mathrm{O}\right)$. Other estimates of the meltwater isotopic content based on a slightly different approach [Petit et al., 2005] give similar values.

[61] Note that the $\delta^{18} \mathrm{O}$ content of meltwater is significantly lower (by $0.97 \%$ ) than that of lake ice, the fact used by Bulat et al. [2003] and Petit et al. [2005] to prove the influence of hydrothermal processes. For $\delta \mathrm{D}$ this difference is about $2.6 \%$, which is not statistically significant.

[62] Another model estimate suggests that LV is in steady state without taking into account this hydrothermal source, thus implying that the lake ice isotopic content is equal to that of meltwater [Royston-Bishop et al., 2004]. This contradicts the fact that the lake ice isotopic composition deviates significantly from both Vostok and Dome B meteoric water lines (Figure 7a).
[63] In Figure 7b, we plotted the results of model simulations of the freezing water isotope content for four different scenarios. All the scenarios assume steady state of LV and (except scenario 4) a complete mixing between melt and lake water. The first scenario assumes that the lake water is in equilibrium with the lake ice. This scenario is unlikely, as supercooled conditions are expected in the freezing water [Souchez et al., 2000] with frazil ice crystal formation. Most probably, the portion of frazil crystals is about $50 \%$ [Petit et al., 2005]. Points 2 and 3 in Figure $7 \mathrm{~b}$ account for this scenario for minimum and maximum supercooling rates, correspondingly. The range between these two points represents the most likely lake water isotopic composition, about $-449 \%$ in $\delta \mathrm{D}$ and $-57.9 \%$ in $\delta^{18} \mathrm{O}$. In the case of poor mixing the isotopic content of the resident lake water is somewhere in the vicinity (slightly below) of the water-ice freezing line. This scenario is shown in Figure $7 \mathrm{~b}$ by point 4 assuming a $20 \%$ contribution of meltwater $(\sigma=0.8)$, point 2 being the isotopic content of the mixed water.

\subsubsection{Isotopic Content of Hydrothermal Waters}

[64] According to equation (4), a precise estimate of the isotopic content $\left(R_{H T}\right)$ of hydrothermal waters would not be possible even if we knew the isotopic content of meltwater exactly, because of the uncertainties associated with the relative contribution of this source (parameter $q_{H T}$ ) and with the isotopic content of the lake water. Accepting the most likely lake water isotopic composition given in the previous section, we defined the line of the most likely hydrothermal values (Figure $7 \mathrm{~d}$ ). Note that the slope of this line is 2.7 , which agrees well with expected value of 0-4 [Hoefs, 2004]. The distance between the hydrothermal and the lake water isotopic content inversely depends on the $q_{H T}$ parameter (the point HTW in Figure 7d, shown as an example, corresponds to $q_{H T}$ equal to 0.35 ). Typical isotopic enrichment of water in hydrothermal systems is of the order of $10 \%$, up to $15-$ $20 \%$, for oxygen [Hoefs, 2004]. Assuming a plausible value of 7\%o and accepting the $S_{w-H T}$ slope obtained here (2.7), we come to the estimation of -430.5 and $-50.9 \%$ for $\delta \mathrm{D}$ and $\delta^{18} \mathrm{O}$ (beyond the limits of Figure $7 \mathrm{~d}$ ), and $q_{H T}$ value of 0.14. Since the meltwater flux in Lake Vostok is about $10^{3}-10^{4} \mathrm{~m}^{3} / \mathrm{km}^{2}$ per year this corresponds roughly to $1000 \mathrm{~m}^{3} / \mathrm{km}^{2}$ per year of hydrothermal input. This is the same order of magnitude (or less) as the total discharge of all the hot springs in Japan [Fujio, 1999] averaged over the whole area of the country.

[65] If we assume that the hydrothermal source contributes independently to the lake volume, then its isotopic content may be defined from equation (5). In this case the lake ice isotopic content is simply a weighted mean of those of the two sources. Assuming again a 14\% contribution of this hydrothermal source gives its isotopic values as being equal to -426.6 and $-50.3 \%$ for $\delta \mathrm{D}$ and $\delta^{18} \mathrm{O}$, which means about $7.6 \%$ enrichment for oxygen-18, and a $\delta \mathrm{D}-\delta^{18} \mathrm{O}$ slope of $\sim 3.0$ between this source and the lake water.

[66] The values of the hydrothermal water isotope content and flux obtained in this section are not in contradiction with the expected ones. Thus, though available data do not allow precise determination of the LV hydrothermal source characteristics, we conclude that we have some constraints on their possible range.

[67] In the above calculations we suggest a full mixing of hydrothermal and lake waters, which is not supported 

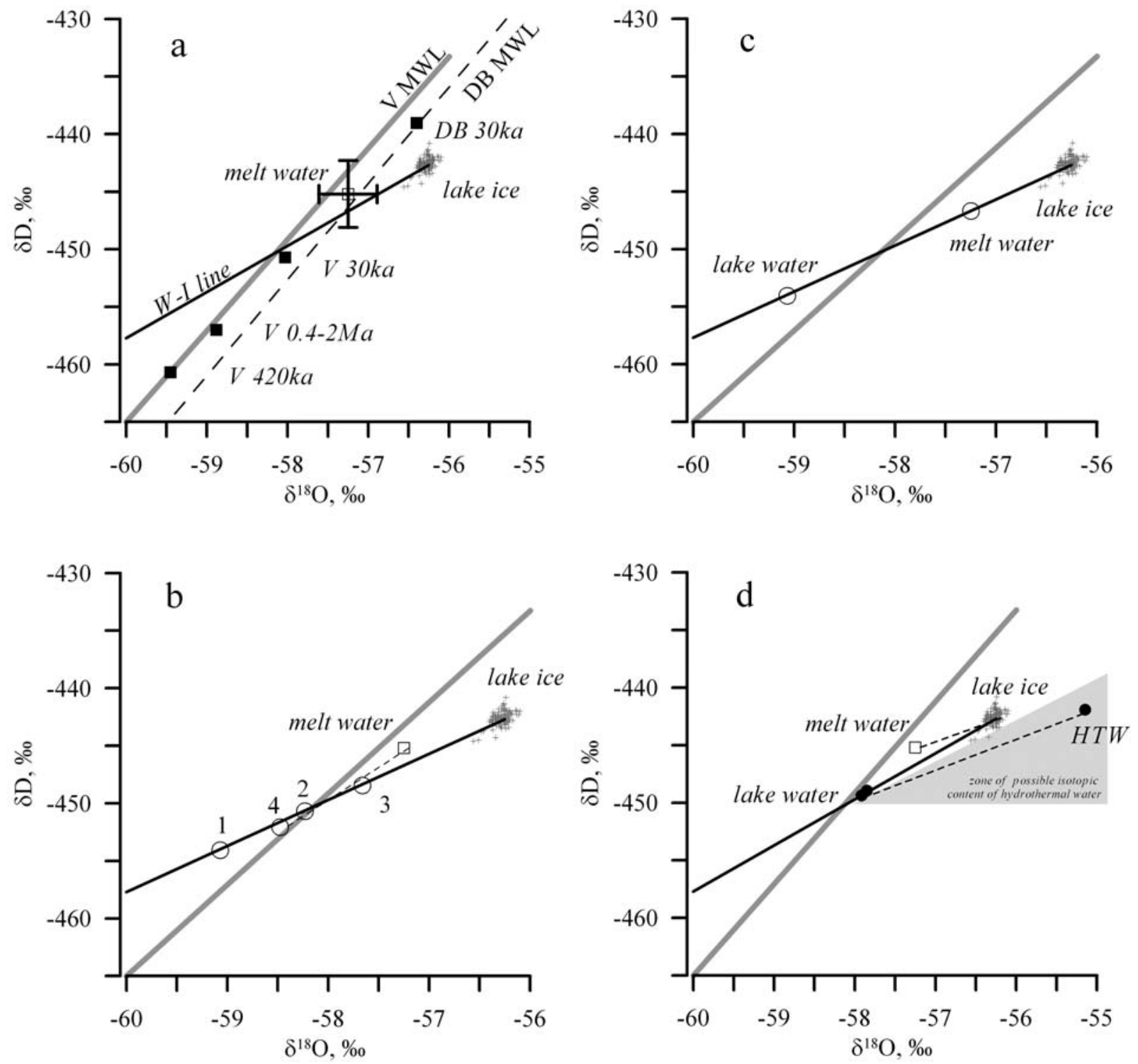

Figure 7. Components of isotopic budget of Lake Vostok. (a) Estimation of LV meltwater isotopic composition of V MWL and DB MWL (the Meteoric Water Lines for Vostok and Dome B with slopes of about 8). V $420 \mathrm{ka}, \mathrm{V} 30 \mathrm{ka}$, and V 0.4-2 Ma are the mean Vostok isotopic values over the last $420 \mathrm{ka}$, $30 \mathrm{ka}$, and in the depth interval 3310-3538 m(0.4-2 Ma), respectively. DB $30 \mathrm{ka}$ is the mean isotopic value at Dome B over the last $30 \mathrm{ka}$, and meltwater is the Lake Vostok meltwater isotopic composition (with error bars), estimated as Dome B mean isotopic content over the past 0.4-2 Ma (meltwater = $D B 30 \mathrm{ka}-V 30 \mathrm{ka}+V 0.4-2 \mathrm{Ma}$ ). W-I line corresponds to the lake ice freezing line (with a slope of about 4). (b) The LV water isotopic compositions (numbered points) for different scenarios: scenario 1 is water freezing in equilibrium with lake ice; scenarios 2 and 3 are the scenarios when $50 \%$ of lake ice consist of frazil crystals formed at the minimum and maximum, respectively, rate of crystal growth; and senario 4 assumes a poor mixing of the lake and meltwaters, so that $20 \%$ of the meltwater and $80 \%$ of the resident lake water (with isotopic composition shown by point 4) contribute to the isotopic content of the freezing water, which in this case equals the isotopic composition of the freezing lake water for scenario 2 . Any change in mixing ratio ( $\sigma$ in equation (3)) will shift the isotopic content of the freezing water (and thus of the lake ice) along the dashed line with a slope between 4 and 8. (c) A simulated lake water, meltwater, and lake ice isotopic composition in case that LV is not in a steady state and there is no additional water source. (d) Plausible estimates of the major components of the LV isotopic budget. The isotopic content of freezing water, from which the lake ice forms, is defined as an average of scenarios 2 and 3 (Figure 7b). The lake water content is estimated assuming a $10 \%$ contribution of meltwater to the freezing water; the isotopic content of the hydrothermal water corresponds to $q_{H T}=0.35$ in equation (4). The gray color depicts a possible range of the hydrothermal water isotopic content, as defined assuming a slope of 0 to 4 between the lake and hydrothermal waters [Hoefs, 2004]. 
by the ice core data (section 4.1.). At this stage, it does however not make sense to introduce a partial mixing into the model, since it will not considerably change the estimates of the LV isotopic budget.

\subsubsection{Unsteady State Scenario for $\mathbf{L V}$}

[68] In Figure 7c we schematically show a situation where LV is not in a steady state, so the isotopic composition of the meltwater does not equal that of lake ice (no hydrothermal source is assumed here). The isotopic content of the lake water, the meltwater and the lake ice are assumed to lie along the line with a slope of about 4, as shown in Figure 7c. Note that this scheme resembles the likely distribution of isotopic composition of meltwater and lake ice shown in Figure 7a. Keeping in mind possible error, one may assume that the meltwater isotopic composition is situated on the freezing line (W-I line) in Figure 7a. This means that accounting only for the bulk isotopic composition of lake ice does not allow ruling out a possibility that LV is not in steady state. If so, we would likely observe a distinct negative trend in the lake ice isotope series with the $S_{\text {ice }}$ slope of 4 , as the lake ice composition would tend to that of the meltwater, which is not confirmed by the data (Figure 2).

[69] Alternatively, it is possible that the isotopic composition of the ice remains constant in a non steady state (in terms of lake mass) scenario. This would be the case if the change of the lake water isotopic composition was compensated by increasing lake volume due to extra meltwater income [Petit et al., 2008]. The calculations show that the observed shift between meltwater and lake ice could be explained by meltwater excess of $20 \%$ (corresponding to a $q$ parameter of about 0.83 in our model), and that isotopic equilibrium for lake ice is achieved after about $200 \mathrm{ka}$. Such a significant volume change might have happened if LV had experienced large water floods (jökulhlaups), as mentioned above in section 4.3. However, this scenario does not receive clear support neither from the Vostok ice core climatic record no from the numerous radio echo sounding data collected in the LV area.

[70] Available experimental data show that, at least on the time scale of 5 years, LV and the ice sheet in the region of Vostok Station are presently in a steady state regime [Richter et al., 2008], though this is a too short period to capture possible long-scale changes of LV balance.

\section{Conclusions}

[71] The recent resumption of deep drilling at the Russian Vostok Station has allowed extending the ice core isotopic profile to a depth of $3650 \mathrm{~m}$, thus spanning $41 \mathrm{~m}$ of Lake Ice 2 (clean ice without visible mineral inclusions below $3609 \mathrm{~m}$ depth). Thorough analyses of the whole available accreted ice section (3539-3650 m) with the use of an improved isotopic model of Lake Vostok show that the isotopic composition of lake ice is a complex function of a number of factors that influence the isotopic composition of the freezing lake water and the fractionation process during ice formation.

[72] In particular, changes in isotopic composition of Lake Ice 1 suggest a significant variability of physical conditions prevailing at ice formation, which might affect the volume concentration and/or the growth rate of frazil crystals. There is also evidence that the isotopic content of freezing water has been varying during formation of Lake Ice 1 partly due to the varying conditions of the meltwater access to the ice formation site.

[73] Ice 2 is characterized by a noncovariant behavior of $\delta \mathrm{D}$ and $\delta^{18} \mathrm{O}$. The flat pattern of oxygen-18 suggests very stable conditions in terms of ice formation processes and of meltwater source, whereas the variability of the deuterium profile points out to significant influence of a hydrothermal source.

[74] The observed short-term (compared to the lake renewal time) variability of the lake ice isotopic content, caused by the influence of melt and hydrothermal waters, implies a poor mixing of these fluids with the resident water of the main lake body. This conclusion may have important consequences for considering the water renewal time, the chemical and gas balance and the microbiological content of Lake Vostok. A poorly mixed lake may permit ecological niches to exist where microbial life can hide from high oxygen concentrations likely typical for the lake.

[75] Despite the difference in short-term variability, the mean isotopic contents of Ice 1 and Ice 2 are similar, with no sharp transition being observed between them, which points to overall similarity of ice formation conditions for these two core sections. The average isotopic content for the whole available lake ice core is -442.6 and $-56.28 \%$ for $\delta \mathrm{D}$ and $\delta^{18} \mathrm{O}$. The estimated isotopic content of meltwater source is $-445.2 \pm 2.9 \%$ o $(\delta \mathrm{D})$ and $-57.25 \pm 0.36 \%$ o $\left(\delta^{18} \mathrm{O}\right)$. As for the hydrothermal source, its isotopic content cannot be estimated with satisfying accuracy based on the available data, but one of the plausible scenarios gives $-430.5 \%$ for $\delta \mathrm{D}$ and $-50.9 \%$ for $\delta^{18} \mathrm{O}$. Finally, the isotopic content of the water that freezes on the ice sheet bottom in the southern part of LV is estimated to be $-449 \%$ for $\delta \mathrm{D}$ and $-57.9 \%$ for $\delta^{18} \mathrm{O}$.

[76] The observed shift between the isotopic compositions of the meltwater and of the lake ice does not rule out the possibility that the whole system is not in steady state on the time scale of the order of $10^{5}$ years. The alternative and more realistic explanation accepted in this study implies significant contribution of an hydrothermal source to the hydrological regime of LV, the scenario supported by a number of independent studies [Bulat et al., 2004; de Angelis et al., 2004; Leitchenkov et al., 2005; Studinger et $a l ., 2003$ ] including the new data on distribution of helium isotopes in the deepest part of Lake Ice 2 (P. Jean-Baptist, personal communication, 2009).

[77] Future studies should focus on the analyses and interpretation of small-scale (of the order of 10-100 years) isotopic variability in ice core, as well as on the estimate of possible past changes of LV isotopic budget components. We also expect to improve the isotopic method of LV studies. As an example, the processes leading to the formation of the lake ice isotopic composition could be further constrained by data on oxygen- 17 content. The continuation of the deep ice coring at Vostok will provide us with the new accreted ice formed in the close vicinity of the station. Younger ice age will result in better preservation of the short-term natural isotopic variability after diffusive smoothing. In the deeper ice core (roughly at $3725 \mathrm{~m}$ ), one could also expect to find a new interval with visible mineral inclusions, since Vostok flow line passes close to a small 
subglacial island located about $10 \mathrm{~km}$ upstream of the station (Figure 1).

[78] In case of penetration into Lake Vostok [Inman, 2007], a sample of subice water just below the glacier bottom will be taken. This will allow direct measurement of the lake water isotopic composition and of effective waterice isotope fractionation coefficient. The latter will put a strong constraint on the mechanism of lake ice formation and thereby facilitate estimation of the major components of the LV isotopic budget thus improving our knowledge about the hydrological regime of the lake and the scale of its hydrothermal activity.

\section{Notation List}

$L_{e f}$ effective diffusion length.

$M$ a component of mass balance of $\mathrm{LV}\left(M_{l}\right.$ for lake mass, $M_{\text {melt }}$ for meltwater mass).

$q$ ratio of LV mass outcome to $M_{\text {melt }} ; q_{H T}$ - ratio of hydrothermal water mass income to $M_{m e l t}$.

$R$ concentration of heavy isotopic species $\left(R_{l}\right.$ for lake water, $R_{\text {melt }}$ for meltwater, $R_{H T}$ for hydrothermal water, $R_{\text {ice }}$ for lake ice).

$S$ slope (regression coefficient) between changes of oxygen-18 and deuterium $\left(\mathrm{d} \delta \mathrm{D} / \mathrm{d} \delta^{18} \mathrm{O}\right) ; \mathrm{S}$ may be applied to temporal/depth/spatial isotopic variability in ice $\left(S_{i c e}\right)$, in meltwater $\left(S_{m e l t}\right)$, in hydrothermal water $\left(S_{H T}\right)$, etc, or to the line connecting isotopic values of water and ice forming from this water $\left(S_{w-i}\right)$, as well as to the line connecting isotopic content of hydrothermal water with that of lake water feeding the hydrothermal system $\left(S_{w-H T}\right)$.

$\alpha$ effective isotopic fractionation coefficient at waterice interface.

$\delta \quad$ isotopic content in per mil notation $\left(\delta=\frac{R_{S A}-R_{S T}}{R_{S} t} \times\right.$ 1000 , where $R_{S A}=R$ in sample, and $R_{S T}=R$ in standard water).

$\delta \mathrm{D}$ deuterium isotopic contents.

$\delta^{18} \mathrm{O}$ oxygen-18 isotopic contents.

$\sigma$ mixing ratio of meltwater and resident lake water.

[79] Acknowledgments. This work is a contribution to Project 2 of the Subprogram "Antarctica" of the Russian Federal Targeted Program "World Ocean." The logistic support at Vostok was provided by the Russian Antarctic Expedition. We thank the drilling team of the St. Petersburg Mining Institute (N. Vassiliev, V. Zubkov, A. Krassilev, and many others) for providing us with the high-quality ice core from extreme depths, which makes our study possible. We are also grateful to the staff of LSCE, NBI, and VSEGEI (O. Cattani, S. Falourd, A. Boas, E. Prilepsky, and E. Prasolov) for performing the isotopic measurements. The work has been carried out in the frame of the French-Russian collaborative project (GDRE) Vostok and also financially supported by RFBR grant $05-05-65248$. We thank S. Bulat, A. Salamatin, S. Popov, and P. Jean-Baptiste for valuable discussions; two anonymous reviewers for the criticism and suggested improvements; and S. Popov for providing the data for Figure 1. We also thank M. Town who helped us to refine the English of the manuscript.

\section{References}

Bell, R. E., et al. (2002), Origin and fate of Lake Vostok water frozen to the base of the east Antarctic ice sheet, Nature, 416, 307-310, doi:10.1038/ 416307a.

Bulat, S. A., et al. (2003), Limitations for life in Lake Vostok, Antarctica, paper presented at Joint Spring Meeting 2003, AGU, Nice, France.

Bulat, S. A., et al. (2004), DNA signature of thermophilic bacteria from the aged accretion ice of Lake Vostok, Antarctica: Implications for searching life in extreme icy environments, Int. J. Astrobiol., 3(1), 1-12, doi: $10.1017 / \mathrm{S} 1473550404001879$.

Christner, B. C., et al. (2006), Limnological conditions in subglacial Lake Vostok, Antarctica, Limnol. Oceanogr., 51(6), 2485-2501.

Craig, H. (1961), Isotopic variations in meteoric waters, Science, 133, 1702-1703, doi:10.1126/science.133.3465.1702.

Craig, H. (1963), The isotopic geochemistry of water and carbon in geothermal areas, in Nuclear Geology in Geothermal Areas, edited by E. Tongiorgi, pp. 17-53, Cons. Naz. delle Ric., Spoleto, Italy.

Criss, R. E., et al. (1982), Effects of regional uplift, deformation, and meteoric-hydrothermal metamorphism on K-Ar Ages of biotites in the southern half of the Idaho batholith, J. Geophys. Res., 87(B8), 7029-7046, doi:10.1029/JB087iB08p07029.

de Angelis, M., et al. (2004), Contributions of an ancient evaporitic-type reservoir to subglacial Lake Vostok chemistry, Earth Planet. Sci. Lett. 222, 751-765, doi:10.1016/j.epsl.2004.03.023.

de Angelis, M., et al. (2005), Brine micro-droplets and solid inclusions in accreted ice from Lake Vostok (east Antarctica), Geophys. Res. Lett., 32 , L12501, doi:10.1029/2005GL022460.

Delmonte, B., et al. (2004), First characterization and dating of east Antarctic bedrock inclusions from subglacial Lake Vostok accreted ice, Environ. Chem., 1, 90-94, doi:10.1071/EN04029.

Driesner, T. (1997), The effect of pressure on deuterium-hydrogen fractionation in high-temperature water, Science, 277(5327), 791-794, doi:10.1126/science.277.5327.791.

Ekaykin, A. A., et al. (2002), Spatial and temporal variability in isotope composition of recent snow in the vicinity of Vostok Station: Implications for ice-core interpretation, Ann. Glaciol., 35, 181-186, doi:10.3189/ 172756402781816726

Ekaykin, A. A., et al. (2004), The changes in isotope composition and accumulation of snow at Vostok Station over the past 200 years, Ann. Glaciol., 39, 569-575, doi:10.3189/172756404781814348.

Ekaykin, A. A., et al. (2005), Isotopic composition of subglacial Lake Vostok water (in Russian), Mater. Glyatsiol. Issled., 98, 92-99.

Erlingsson, U. (2006), Lake Vostok behaves like a 'captured lake' and may be near to creating an Antarctic jokulhlaup, Geogr. Ann. Ser. A, 88(1), 1-7, doi:10.1111/j.0435-3676.2006.00278.x.

Evatt, G. W., et al. (2006), Subglacial floods beneath ice sheets, Philos. Trans. R. Soc. London Ser. A, 364, 1769-1794, doi:10.1098/rsta. 2006.1798.

Fricker, H. A., et al. (2007), An active subglacial water system in west Antarctica mapped from space, Science, 315(5818), 1544-1548, doi:10.1126/ science. 1136897 .

Fujio, A. (1999), Change and present condition of hot spring resources of Hokkaido on the basis of the data from used hot springs in each prefecture of Japan, Rep. Geol. Surv. Hokkaido, 70, 27-43.

Giggenbach, W. F. (1992), Isotopic shifts in water from geothermal and volcanic systems along convergent plate boundaries and their origin, Earth Planet. Sci. Lett., 113, 495-510, doi:10.1016/0012-821X(92) 90127-H.

Gilg, H. A., and S. M. F. Sheppard (1996), Hydrogen isotope fractionation between kaolinite and water revisited, Geochim. Cosmochim. Acta, 60(3), 529-533, doi:10.1016/0016-7037(95)00417-3.

Hoefs, J. (2004), Stable Isotope Geochemistry, 244 pp., Springer, Berlin.

Hori, A., et al. (2004), Ice-lattice distortion along the deepest section of the Vostok core from X-ray diffraction measurements, Ann. Glaciol., 39, 501-504, doi:10.3189/172756404781814528.

Ikingura, J. R., et al. (1989), Hydrothermal alteration and oxygen and hydrogen isotope geochemistry of the $\mathrm{D}-68$ zone $\mathrm{Cu}-\mathrm{Zn}$ massive sulfide deposit, Noranda district, Quebec, Canada, Mineral. Petrol., 40, 155-172, doi:10.1007/BF01164326.

Inman, M. (2007), The dark and mushy side of a frozen continent, Science, 317(5834), 35-36, doi:10.1126/science.317.5834.35.

Jean-Baptiste, P., et al. (2001), Constraints on hydrothermal processes and water exchange in Lake Vostok from helium isotopes, Nature, 411(6836), 460-462, doi:10.1038/35078045.

Jean-Baptiste, P., et al. (2003), Helium signature and seismotectonic activity in Lake Vostok, paper presented at Joint Spring Meeting 2003 AGU, Nice, France.

Johnsen, S. J., et al. (2000), Diffusion of stable isotopes in polar firn and ice: The isotope effect in firn diffusion, in Physics of Ice Core Records, edited by T. Hondoh, pp. 121-140, Hokkaido Univ. Press, Sapporo, Japan.

Jouzel, J., and R. Souchez (1982), Melting-refreezing at the glacier sole and the isotopic composition of the ice, J. Glaciol., 28(98), 35-42.

Jouzel, J., et al. (1995), The two-step shape and timing of the last deglaciation in Antarctica, Clim. Dyn., 11, 151-161, doi:10.1007/BF00223498.

Jouzel, J., et al. (1999), More than $200 \mathrm{~m}$ of lake ice above subglacial Lake Vostok, Antarct. Sci., 286, 2138-2141. 
Jouzel, J., et al. (2007), Orbital and millenial Antarctic climate variability over the past 800,000 years, Science, 317, 793-796, doi:10.1126/ science. 1141038 .

Kudryashov, B. B., et al. (2000), Deep ice coring at Vostok Station (east Antarctica) by an electromechanical drill, in Ice Drilling Technologies 2000, Mem. Natl. Inst. Polar Res. Ser., vol. 56, edited by N. Azuma and Y. Fujii, pp. 91-102, Natl. Inst. of Polar Res., Tokyo.

Leitchenkov, G. L., et al. (2005), Geological nature of subglacial Lake Vostok in East Antarctica (in Russian), Mater. Glyatsiol. Issled., 98, 81-91.

Leitchenkov, G. L., et al. (2007), Insight into the geology of the east Antarctic hinterland: A study of sediment inclusions from ice cores of the Lake Vostok borehole, in Antarctica: A Keystone in a Changing World-Online Proceedings of the Tenth International Symposium on Antarctic Earth Sciences, edited by A. K. Cooper et al., 141 p., U.S. Geol. Surv., Reston, Va.

Lipenkov, V., and V. A. Istomin (2001), On the stability of air clathratehydrate crystals in subglacial Lake Vostok, Antarctica (in Russian), Mater. Glyatsiol. Issled., 91, 138-149.

Mayer, C., et al. (2003), Salinity impact on water flow and lake ice in Lake Vostok, Antarctica, Geophys. Res. Lett., 30(14), 1767, doi:10.1029/ 2003GL017380.

McKay, C. P., et al. (2003), Clathrate formation and the fate of noble and biologically useful gases in Lake Vostok, Antarctica, Geophys. Res. Lett., 30(13), 1702, doi:10.1029/2003GL017490.

Montagnat, M., et al. (2001), High crystalline quality of large single crystals of subglacial ice above Lake Vostok (Antarctica) revealed by hard X-ray diffraction, Earth Planet. Sci. Lett., 333, 419-425.

Morasch, B., et al. (2001), Stable hydrogen and carbon isotope fractionation during microbal toluene degradation: Mechanistic and environmental aspects, Appl. Environ. Microbiol., 67(10), 4842-4849, doi:10.1128/ AEM.67.10.4842-4849.2001.

Pattyn, F. (2008), Investigating the stability of subglacial lakes with a full Stokes ice-sheet model, J. Glaciol., 54(185), 353-361, doi:10.3189/ 002214308784886171.

Petit, J. R., et al. (1999), Climate and atmospheric history of the past 420,000 years from the Vostok ice core, Antarctica, Nature, 399(6735), 429-436, doi:10.1038/20859.

Petit, J. R., et al. (2005), Lake Vostok, Antarctica: Exploring a subglacial lake and searching for life in an extreme environment, in Lectures in Astrobiology, edited by M. Gargaud et al., pp. 227-288, Springer, Berlin.

Petit, J. R., et al. (2008), Has water volume of the Vostok subglacial lake doubled since the last 0.5 millions years? A hint from balance of stable isotope, paper presented at Open Science Conference, Sci. Comm. for Antarct. Res., Int. Arctic Sci. Comm., St. Petersburg, Russia.

Polya, D. A., et al. (2000), Evolution and paragenetic context of low $\delta \mathrm{D}$ hydrothermal fluids from the Panasqueira W-Sn deposite, Portugal: New evidence from microthermometric, stable isotope, noble gas and halogen analyses of primary fluid inclusions, Geochim. Cosmochim. Acta, 64(19), 3357-3371, doi:10.1016/S0016-7037(00)00459-2.

Popov, S. V., and V. N. Masolov (2007), Forty-seven new subglacial lakes in the $0-110^{\circ} \mathrm{E}$ sector of east Antarctica, J. Glaciol., 53(181), 289-297, doi: $10.3189 / 172756507782202856$.

Rempel, A. W., and J. S. Wettlaufer (2003), Isotopic diffusion in polycrystalline ice, J. Appl. Phys., 49(166), 397-406.

Richter, A., et al. (2008), Observational evidence on the stability of the hydro-glaciological regime of subglacial Lake Vostok, Geophys. Res. Lett., 35, L11502, doi:10.1029/2008GL033397.

Royston-Bishop, G., et al. (2004), Is Vostok Lake in steady state?, Ann. Glaciol., 39, 490-494, doi:10.3189/172756404781813853.

Royston-Bishop, G., et al. (2005), Incorporation of particulates into accreted ice above subglacial Vostok Lake, Antarctica, Ann. Glaciol., 40, 145-150, doi:10.3189/172756405781813555.

Salamatin, A. N., et al. (2003), An estimate of LV isolation time from a sensitivity experiments for the melting area, paper presented at Joint Spring Meeting 2003, AGU, Nice, France.
Salamatin, A. N., et al. (2004), Vostok (Antarctica) ice-core time-scale from datings of different origins, Ann. Glaciol., 39, 283-292.

Salamatin, A. N., et al. (2010), Ice flow line modeling in ice core data interpretation: Vostok Station (east Antarctica), in Physics of Ice Core Records, edited by T. Hondoh, Hokkaido Univ. Press, Sapporo, Japan, in press.

Satake, H., and S. Matsuo (1984), Hydrogen isotopic fractionation factor between brucite and water in the temperature range from $100^{\circ}$ to $510^{\circ} \mathrm{C}$, Contrib. Mineral. Petrol., 86, 19-24, doi:10.1007/BF00373707.

Siegert, M. J., et al. (2001), Physical, chemical and biological processes in Lake Vostok and other Antarctic subglacial lakes, Nature, 414, 603-609, doi: $10.1038 / 414603 \mathrm{a}$.

Siegert, M. J., et al. (2003), The hydrochemistry of Lake Vostok and the potential for life in Antarctic subglacial lakes, Hydrol. Processes, 17, 795-814, doi:10.1002/hyp.1166.

Souchez, R., and J. Jouzel (1984), On the isotopic composition in $\mathrm{dD}$ and d180 of water and ice during freezing, J. Glaciol., 30(106), 369-372.

Souchez, R., et al. (2000), Ice formation in subglacial Lake Vostok, central Antarctica, Earth Planet. Sci. Lett., 181, 529-538, doi:10.1016/S0012821X(00)00228-4.

Souchez, R., et al. (2004), Reassessing Lake Vostok's behavior from existing and new ice core data, Earth Planet. Sci. Lett., 217, 163-170, doi:10.1016/ S0012-821X(03)00588-0.

Stievenard, M., et al. (1994), Mass spectrometry analysis of water stable isotopes: Reconstruction of past climates from polar ice cores, Analusis Mag., 22(7), 21-24

Studinger, M., et al. (2003), Ice cover, landscape setting, and geological framework of Lake Vostok, east Antarctica, Earth Planet. Sci. Lett., 205, 195-210, doi:10.1016/S0012-821X(02)01041-5.

Thoma, M., et al. (2007), Modeling mixing and circulation in subglacial Lake Vostok, Antarctica, Ocean Dyn., 57, 531-540, doi:10.1007/ s10236-007-0110-9.

Tsyganova, E. A., and A. N. Salamatin (2004), Non-stationary temperature field simulation along the ice flow line "ridge B - Vostok Station," east Antarctica, Mater. Glyatsiol. Issled., 97, 57-70.

Vidal, V. M. V., et al. (1981), Coastal submarine hydrothermal activity off northern Baja California: 2. Evolutionary history and isotope geochemistry, J. Geophys. Res., 86(B10), 9451-9468, doi:10.1029/ JB086iB10p09451.

Vuataz, F. D., and F. Goff (1986), Isotope geochemistry of thermal and nonthermal waters in the Valles Caldera, Jemez Mountains, northern New Mexico, J. Geophys. Res., 91(B2), 1835-1853, doi:10.1029/ JB091iB02p01835.

Walsh, D. (2002), A note on eastern-boundary intensification of flow in Lake Vostok, Ocean Modell., 4, 207-218, doi:10.1016/S1463-5003(01) 00018-X.

Wells, M. G., and J. S. Wettlaufer (2008), Circulation in Lake Vostok: A laboratory analogue study, Geophys. Res. Lett., 35, L03501, doi:10.1029/ 2007GL032162

Wingham, D. J., et al. (2006), Rapid discharge connects Antarctic subglacial lakes, Nature, 440, 1033-1036, doi:10.1038/nature04660.

Wuest, A., and E. Carmack (2000), A priori estimates of mixing and circulation in the hard-to-reach water body of Lake Vostok, Ocean Modell., 2, 29-43, doi:10.1016/S1463-5003(00)00007-X.

$\mathrm{Xu}$, H.-L., et al. (2006), Geochemistry of geopressured hydrothermal waters in the Niigata sedimentary basin, Japan, Isl. Arc, 15, 199-209, doi:10.1111/j.1440-1738.2006.00509.x.

A. A. Ekaykin and V. Y. Lipenkov, Arctic and Antarctic Research Institute, 38 Beringa St., 199397 St. Petersburg, Russia. (ekaykin@aari.nw.ru) S. Johnsen, Niels Bohr Institute, Juliane Maries Vej 30, DK-2100 Copenhagen, Denmark.

J. Jouzel and V. Masson-Delmotte, Laboratoire des Sciences du Climat et de 1'Environnement, CEA, Point Courrier 129, F-91191 Gif-sur-Yvette, France.

J. R. Petit, Laboratoire de Glaciologie et Geophisique de l'Environnement, 54 Rue Moliere, F-38402 St. Martin d'Hères, France. 